\title{
Mechanism of Permeability Evolution for Reservoir Sandstone with Different Physical Properties
}

\author{
Xianshan Liu $\mathbb{D}^{1,2}$ Ming Xu $\mathbb{D}^{1,},{ }^{1,2}$ and Ke Wang ${ }^{1,2}$ \\ ${ }^{1}$ Key Laboratory of New Technology for Construction of Cities in Mountain Area (Chongqing University), \\ Ministry of Education, Chongqing 400045, China \\ ${ }^{2}$ School of Civil Engineering, Chongqing University, Chongqing 400045, China
}

Correspondence should be addressed to Ming Xu; foretech@163.com

Received 15 September 2017; Revised 3 December 2017; Accepted 2 January 2018; Published 22 April 2018

Academic Editor: Wei Wu

Copyright (C) 2018 Xianshan Liu et al. This is an open access article distributed under the Creative Commons Attribution License, which permits unrestricted use, distribution, and reproduction in any medium, provided the original work is properly cited.

\begin{abstract}
Permeability of sandstones with different properties taken from Chongqing reservoirs has been measured and deeply discussed under increasing deviatoric stress. Corresponding to the distinct features in the stress-strain behaviors, the permeability of sandstones is found to evolve with a clear permeability decrease in the initial closure region, a constant permeability value in the elastic region, a permeability increase in the crack initiation and propagation region, a sharp permeability increase in the crack growth region, and a decrease permeability in the residual stage. The results also show that the variation patterns of permeability are similar for two reservoir sandstones under combination of confining pressure and water pressure; however, the strength and permeability are smaller for the sandstone with mud than that without mud, deeply indicating that mud-like materials have a relatively great impact on the mechanical properties and permeability, so mud components cannot be ignored for prediction of reservoir permeability. Furthermore, a statistical damage constitutive model considering hydraulic-mechanical coupling process is presented to calculate the damage variable $D$, illustrating that larger water pressure will result in a relatively smaller damage variables $D$ and corresponding maximum, which explains that the permeability increases more rapidly and is larger for the sandstone without mud than that with mud, and sandstone damage related to corresponding circumferential crack strain and permeability has been investigated, also implying the evolution mechanism of permeability for two sandstones with different physical properties. Therefore, it is worth pointing out that rock physical properties have a great influence on the reservoir permeability under complex extraction conditions and cannot be ignored, which is necessary to improve the recovery ratio and productivity.
\end{abstract}

\section{Introduction}

As a typical kind of sedimentary rock, sandstone is encountered in many oil reservoirs, and its deformation behavior and permeability are significant for understanding the reservoir exploration mechanism. Note that the failure of reservoir rocks and permeability variation is a potential instance considered in the petroleum engineering. Thus, the behavior has become a topic of substantial interests to researchers working in this geoscience field. The microcracks induced by hydraulic pressure or reservoir extraction, however, may drastically enhance the permeability in the disturbed zone of surrounding rocks and hence improve the reservoir permeability and recovery ratio. In the past decades, the permeability variations of rocks during progressive deformation in some rock engineering have been also achieved, which is of paramount importance for deep research on the permeability evolution of reservoir sandstones with different properties.

In recent years, a few researches about the physical properties influencing on the permeability of reservoir rocks are discussed, Han et al. [1] and Xiong et al. [2] conducted some experiments to describe the reservoir physical properties, indicating that different pore structures and volume clay content made an obvious difference in percolation flow capacity and oil productivity. Furthermore, the external disturbances will inevitably change the reservoir structures to form new seepage channels, resulting in different evolution mechanism of permeability. Therefore, the issue about the permeability variations is significant to be solved especially for different reservoirs development. 
And for the permeability determination of different rocks, Ma et al. [3] and Alam et al. [4] carried out the triaxial compression tests to measure the granite permeability, explaining that the permeability evolution was caused by rock damage, which provides a method to analyze the permeability variation under loading conditions. Furthermore, some researches on the permeability evolution of rocks under hydromechanical coupling conditions have been discussed, Tan et al. [5] conducted seepage tests on the granite to describe the permeability evolution during the progressive failure process, which replicated the complex hydromechanical coupled behavior of low porous rocks, and Wang and $\mathrm{Xu}$ [6] carried out the permeability tests on limestone and sandstone during the course of deformation and failure; accordingly, the permeability evolution curves were divided into four phases of elastic compression phase, compression stability stage, dramatic increase phase of permeability, and postpeak phase, which is important for research on the permeability variation under multiphysical coupling conditions. Meanwhile, some experiments about the permeability of rocks with other physical properties have been investigated; Zeng et al. [7] measured the mudstone permeability, showing a high stress sensitivity during loading of effective confining pressure, and Zhang [8] discussed the stress-strain permeability behavior of the claystone during damage process, both indicating that mud or clay components will greatly influence the rock permeability, which is useful to understand the permeability of the reservoir sandstone with mud. In addition, for sandstone as a familiar rock, more researches have been implemented; Wang et al. [9], Ding et al. [10], and Yang et al. [11] studied the sandstones permeability under different loading conditions. Zisser and Nover [12] and $\mathrm{Hu}$ et al. [13], respectively, studied the permeability of tight sandstones and damaged sandstone, and French et al. [14] investigated the controls of in situ stress state on fluid flow conduits in lowporosity polyphase sandstone under intact, microfractured, and macrofractured deformation states. And also, Ingrahama et al. [15] and Yang et al. [16] investigated the permeability evolution of the sandstone under high stress or different temperature conditions. Meanwhile, Han et al. [1] and Xiao et al. [17] investigated the permeability of reservoir sandstones with different clay content, providing a powerful alternative in investigating the permeability evolution of the reservoir sandstones under different loads combination.

However, a few researches have been performed to investigate the permeability evolution during complete failure process of reservoir sandstones, which is very important for improvement of oil recovery ratio and productivity capacity. Li et al. [18] carried out the permeability measurement of shale with different fractures under anisotropic true triaxial stress conditions, Dong et al. [19] compared the permeability of sandstone and shale, which are basis for further research on the reservoir permeability, and $\mathrm{Wu}$ et al. [20] investigated the impacts of effective stress and CO2 sorption on the bedding-parallel matrix permeability of the shale and explained CO2 sorption to constrict fluid flow pathways in shale reservoir rocks. Therefore, deep research on the permeability evolution of different reservoir rocks is necessary, and also the comparison of the permeability for different reservoir sandstone can be realized based on above achievements.

Although the permeability characteristics of sandstones have been analyzed in laboratory conditions and in situ compression tests, few have taken into account of the influence of loads combination on the permeability behavior of reservoir sandstones with different physical properties. This study conducts experimental permeability measurements to investigate the relationship of crack propagation and permeability of reservoir sandstones without mud and with mud. And also the damage analysis has been employed to analyze the rock damage evolution and corresponding permeability variation, revealing the mechanism of the permeability evolution caused by rock damage considering the hydromechanical coupling effect.

\section{Testing Principle and Methods}

2.1. Specimens Preparation. To investigate and compare the permeability characteristics of two different reservoir sandstones during loading process under the action of different confining stresses and water pressure, the sandstones taken from western Xindianzi anticline in Chongqing city are selected for the experimental study considering different physical properties. One is sandstone without mud (Figure 1(a)), and the other is with mud (Figure 1(b)). According to the method by the International Society for Rock Mechanics (ISRM), the size of all tested sandstone specimens is cylindrical with $50 \mathrm{~mm}$ in diameter and $100 \mathrm{~mm}$ in length approximately. It is observed from Figure 1 that the sandstone without mud is gray and of smooth surface and bedding is viewed obviously, and the sandstone with mud is yellow including more coarse particles and mud spots in surface. And the X-Ray Diffractions (XRD) shown in Figure 2 indicate that quartz and feldspar are mainly inside the sandstone without mud (Figure 2(a)); however, the quartz and feldspar inside the sandstone with mud are less obvious because of more clay with mud content of $29.8 \%$ (Figure 2(b)). Furthermore, all specimens of two kinds of reservoir sandstones are acoustically detected by the nonmetallic acoustic detector RSM-SY5 (Figure 2(c)), the detected longitudinal wave velocity $V_{p}$ is, respectively, $2.29 \pm 0.1 \mathrm{~km} / \mathrm{s}$ for the sandstone without mud listed in Table 1 and $2.32 \pm 0.1 \mathrm{~km} / \mathrm{s}$ listed in Table 2 for sandstone with mud, also indicating that every group of two reservoir sandstone specimens is uniform to avoid the specimens heterogeneity influencing on the experimental efficiency and accuracy.

\subsection{Experimental Setup}

2.2.1. Experimental Equipment. All tests will be carried out on a rock servocontrolled triaxial equipment named Rock 600-50HT PLUS (Figure 2(d)) manufactured by TOPINDUSTRIE in France. The experimental apparatus consists of triaxial cell with servocontrolled triaxial and circumferential loading systems, a constant-stability pressure equipment, a hydraulic pressure transfer system, a pressure chamber equipment, a hydraulic pressure system, and an automatic 


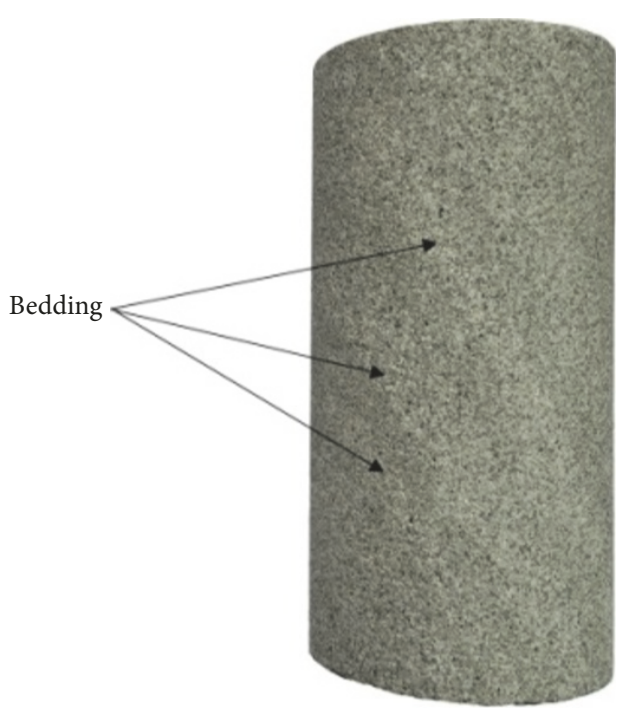

(a) Sandstone without mud and bedding

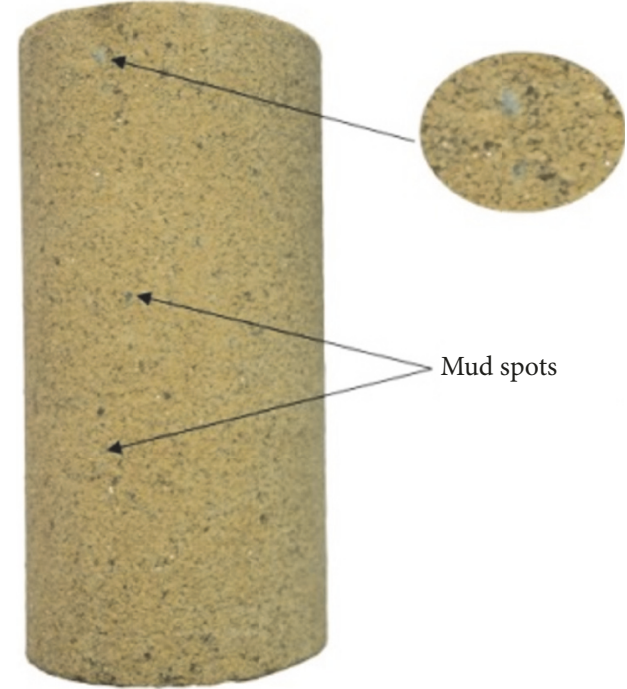

(b) Sandstone with mud and mud spots

Figure 1: Reservoir sandstone and physical properties.

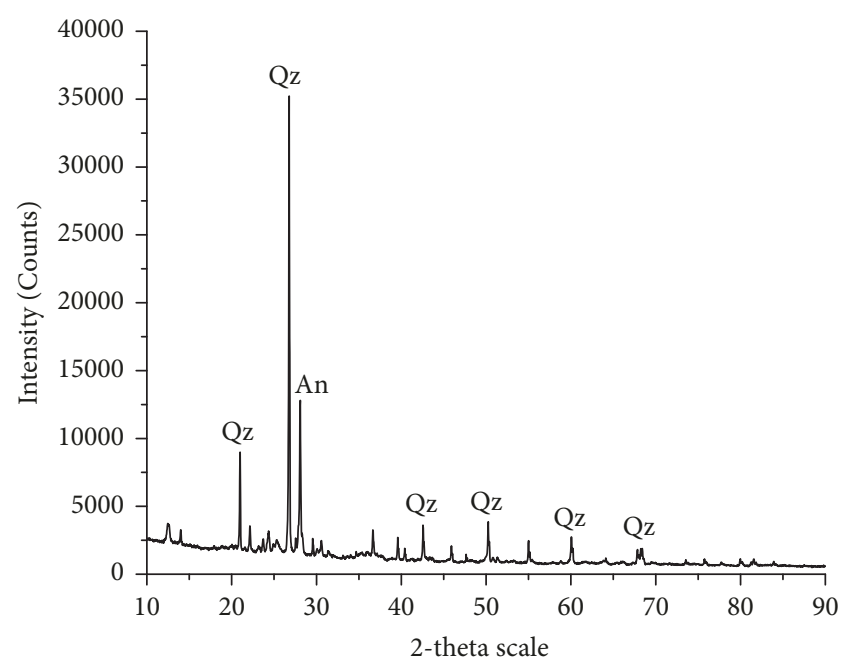

(a) X diffraction pattern of sandstone without mud

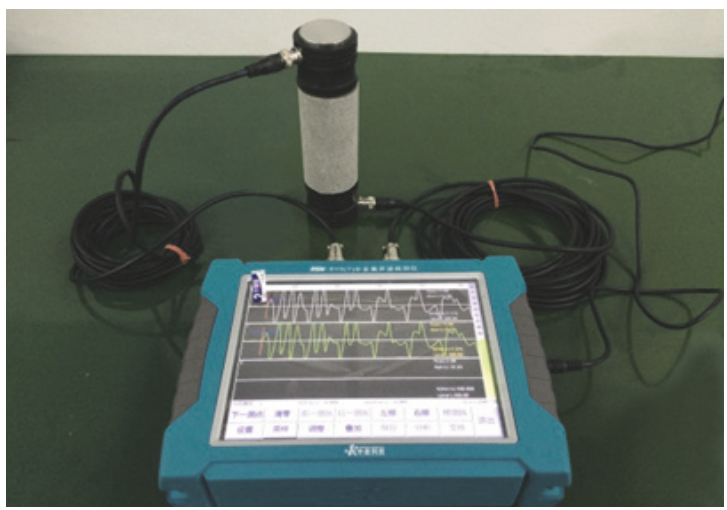

(c) Acoustic detection of the sandstone

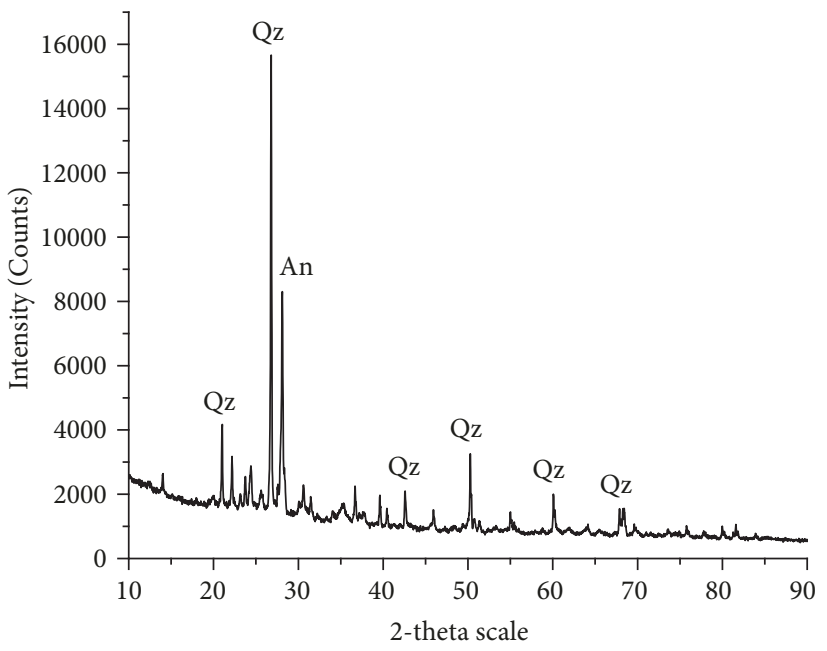

(b) X diffraction pattern of sandstone with mud

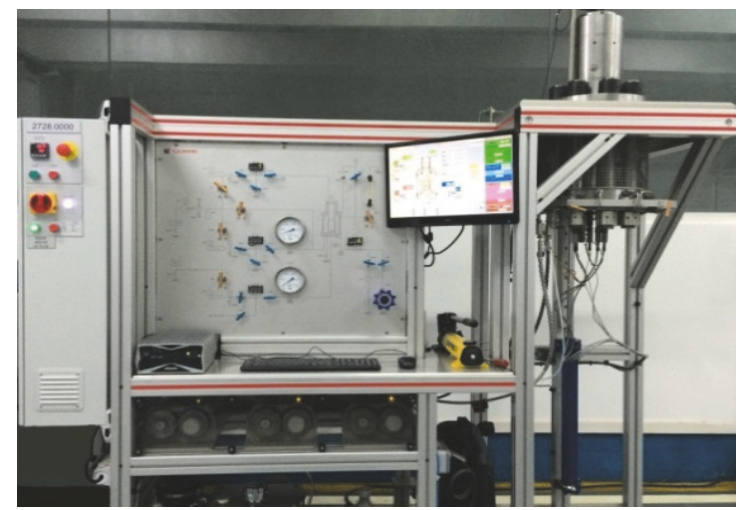

(d) Triaxial equipment

Figure 2: Acoustic detection tests and triaxial equipment. 
TABLE 1: Loading conditions and parameters of sandstones without mud.

\begin{tabular}{lcccc}
\hline $\begin{array}{l}\text { Loading } \\
\text { conditions }\end{array}$ & $\begin{array}{c}\text { Diameter } \\
(\mathrm{mm})\end{array}$ & $\begin{array}{c}\text { Height } \\
(\mathrm{mm})\end{array}$ & $\begin{array}{c}\text { Mass } \\
(\mathrm{g})\end{array}$ & $\begin{array}{c}V_{p} \\
(\mathrm{~km} / \mathrm{s})\end{array}$ \\
\hline C3P0 & 49.82 & 100.20 & 449.00 & 2.326 \\
C3P2 & 49.80 & 100.08 & 448.30 & 2.324 \\
C6P2 & 49.80 & 99.90 & 448.50 & 2.196 \\
C6P3 & 49.82 & 100.04 & 448.70 & 2.252 \\
C6P4 & 49.80 & 99.84 & 448.90 & 2.274 \\
C9P2 & 49.82 & 100.10 & 449.10 & 2.326 \\
C9P6 & 49.82 & 100.00 & 450.10 & 2.328 \\
C15P2 & 49.80 & 100.12 & 446.60 & 2.275 \\
C15P3 & 49.82 & 99.96 & 449.70 & 2.286 \\
C15P4 & 49.82 & 99.88 & 451.80 & 2.320 \\
\hline
\end{tabular}

TABLE 2: Loading conditions and parameters of sandstones with mud.

\begin{tabular}{lcccc}
\hline $\begin{array}{l}\text { Loading } \\
\text { Conditions }\end{array}$ & $\begin{array}{c}\text { Diameter } \\
(\mathrm{mm})\end{array}$ & $\begin{array}{c}\text { Height } \\
(\mathrm{mm})\end{array}$ & $\begin{array}{c}\text { Mass } \\
(\mathrm{g})\end{array}$ & $\begin{array}{c}V_{p} \\
(\mathrm{~km} / \mathrm{s})\end{array}$ \\
\hline C3P0 & 49.72 & 99.88 & 421.74 & 2.381 \\
C3P2 & 49.72 & 99.82 & 421.16 & 2.222 \\
C6P2 & 49.72 & 100.02 & 420.99 & 2.326 \\
C6P3 & 49.72 & 100.06 & 422.64 & 2.367 \\
C6P4 & 49.72 & 99.56 & 424.49 & 2.287 \\
C9P2 & 49.72 & 99.86 & 420.75 & 2.380 \\
C9P6 & 49.72 & 100.00 & 419.84 & 2.343 \\
C15P2 & 49.72 & 99.90 & 418.98 & 2.284 \\
C15P3 & 49.72 & 99.86 & 419.68 & 2.320 \\
C15P4 & 49.72 & 100.10 & 420.79 & 2.326 \\
\hline
\end{tabular}

data collection system. The triaxial cell is capable of performing triaxial compression tests at confining pressures (P2) up to $60 \mathrm{MPa}$, with increasing deviatoric stress (P1) up to $500 \mathrm{MPa}$, with increasing transducer having a resolution of $0.01 \mathrm{MPa}$. The system can deal with the constant-head, constant flow-rate, and transient-pulse permeability tests under low or high confining and water pressures, and constant-head is selected in this paper. And different fluid can be chosen as the pore fluid, depending on the permeability of the tested rocks and testing requirement. The servocontrolled fluid pump can produce pore pressure up to $60 \mathrm{MPa}(\mathrm{P} 3 / \mathrm{P} 4)$. Furthermore, the upstream and downstream fluid pressure can be regulated with pore pressure pumps $\mathrm{P} 3$ and $\mathrm{P} 4$; as a result, the seepage tests can be performed on constant fluid pressure or constant volume condition according to the experimental target.

The testing equipment can be used to perform all controlled tests and data analysis by computer and robotized operations and ensures that all the tests are analyzed safely, timely, and accurately. The apparatus can be used to deal with hydrostatic pressure tests, conventional triaxial compression tests, triaxial seepage tests, chemical erosion tests, and so forth. Four kinds of loading modes including displacement loading, stress loading, strain loading, and flow loading are employed during the testing process according to different experimental requirement. And the apparatus can automatically record all the real-time data every 5 seconds.

2.2.2. Testing Procedure. Before testing, the sandstones samples should be firstly saturated, then vacuumized for 4 hours by the vacuum pump and wet pumped for 4 hours with distilled water, and finally soaked for 16 hours to ensure the specimens full of water. Furthermore, the sandstone specimens are enclosed in a $3 \mathrm{~mm}$ thick Viton rubber jacket and then placed in the sample assembly. Porous spacers are inserted on to the ends of the samples to ensure even distribution of pore pressure over the ends of the samples. When testing, the axial displacement is measured with two displacement LVDTs, and the circumferential deformation is measured with a circumferential sensors attached tightly on the middle portion of the specimen outside the rubber jacket. Considering the influence of the temperature on deformation and seepage response, all the tests are all performed at room temperature $\left(25 \pm 2^{\circ} \mathrm{C}\right)$.

The triaxial seepage tests under different loads combination can be performed as follows. The samples are firstly applied with the confining pressure of the desired value, and this stage the axial stress is proportionally increased to the value of the confining pressure, bringing the samples to an initial isotropic stress or zero deviatoric stress. And then, the saturated specimens are ensured to hold at a constant pore pressure, which means that the upstream pressure (P3) and downstream pressure (P4) are balanced. This step is key to ensure the fluid in a single phase when seepage testing. Afterwards, the deviatoric stress is increased stepwise in the axial load control condition up to each selected deviatoric stress, the axial load is maintained constant, and, after that, the seepage testing is invoked for measurements of the rock permeability. For this steady seepage testing procedure, the permeability of the samples can be calculated by measuring the fluid volume from the pump in a period of time and written by the following [21]:

$$
k=\frac{\mu L V}{A \Delta p \Delta t},
$$

where $k$ is the permeability of the rock $\left(\mathrm{m}^{2}\right) ; \mu$ is the dynamic viscosity of the fluid (water at $T=20^{\circ} \mathrm{C}: 1 \times 10^{-3} \mathrm{~Pa} \cdot \mathrm{s}$ ); $L$ is the specimen height $(\mathrm{m}) ; V$ is the fluid volume $\left(\mathrm{m}^{3}\right)$ from the pump in time $\Delta t ; A$ is the cross-sectional area $\left(\mathrm{m}^{2}\right)$; $\Delta p$ is the fluid pressure difference on the upstream side and downstream side of the specimens $(\mathrm{Pa}) ; \Delta t$ is the seepage time(s).

In order to deeply investigate and compare the permeability of different reservoir sandstones during the triaxial seepage testing process, a series tests coupled with water permeation are conducted on saturated sandstone specimens. The tested sandstone specimen and loading conditions are listed in Tables 1 and 2, in which C6P2 represents the loading condition of confining pressure valued $6 \mathrm{MPa}$ and water pressure valued $2 \mathrm{MPa}$, as well as other expression of loading conditions. 


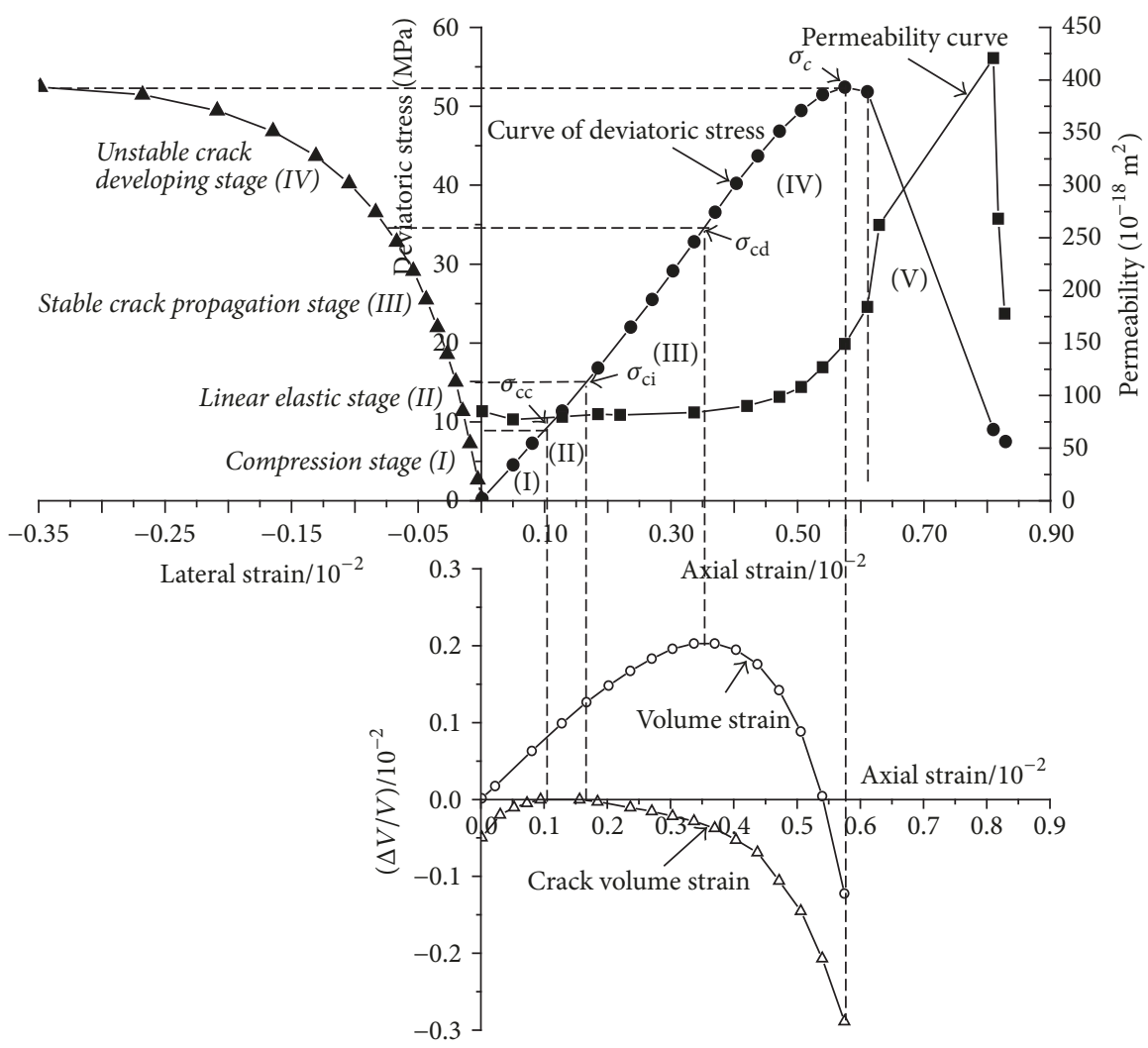

Figure 3: Curves of different strain versus deviatoric stress.

\section{Permeability Tests of Two Kinds of Reservoir Sandstones}

3.1. Relationship of the Strain and Crack Propagation. It is well known that the method of crack volumetric strain proposed by Martin and Chandler [22] has been widely used in triaxial compression tests to describe the crack initiation and propagation characteristics; Xu and Yang [23] described the crack variation and corresponding permeability of the sandstone specimens from coal mine under short-term and long-term triaxial compression, indicating that crack evolution is closely related to the permeability behavior.

And the volume strain $\varepsilon_{v}$ and crack volume strain $\varepsilon_{\mathrm{cv}}$ [22] under triaxial compression can be written by

$$
\begin{aligned}
\varepsilon_{v} & =\varepsilon_{1}+2 \varepsilon_{3} \\
\varepsilon_{\mathrm{cv}} & =\varepsilon_{v}-\frac{(1-2 \nu)\left(\sigma_{1}+2 \sigma_{3}\right)}{E},
\end{aligned}
$$

where $\varepsilon_{v}$ is the volume strain; $\varepsilon_{1}, \varepsilon_{3}$ are the axial strain and lateral strain, respectively; $\sigma_{1}$ is the axial stress; $\sigma_{3}$ are the confining stress; $E$ is the elastic modulus; $v$ is Poisson's ratio.

And the lateral strain [22] can be described by

$$
\varepsilon_{3}=\varepsilon_{e 3}+\varepsilon_{c 3},
$$

where $\varepsilon_{e 3}$ is the elastic strain considering same stress and can be written by (4) based on Hooke's law [22]; $\varepsilon_{c 3}$ is the circumferential crack strain.

$$
\varepsilon_{e 3}=\frac{\left[\sigma_{3}-\nu\left(\sigma_{1}+\sigma_{3}\right)\right]}{E} .
$$

Substituting (4) into (3) gives the expression of the circumferential crack strain $\varepsilon_{c 3}$ as follows:

$$
\varepsilon_{c 3}=\varepsilon_{3}-\frac{\left[\sigma_{3}-v\left(\sigma_{1}+\sigma_{3}\right)\right]}{E} .
$$

Equation (5) indicates that lateral strain, axial pressure, and confining pressures will influence the circumferential crack strain; as shown in Figure 3, there are different curves of axial strain versus deviatoric stress $\sigma_{1}-\sigma_{3}$ and rock permeability, volume strain, and crack volume strain. It can be observed that the curve of the deviatoric stress $\sigma_{1}-\sigma_{3}$ versus axial strain can be divided into five stages [22]: (1) compression stage: closure of the existing microcrack and pores results in the crack volume strain decreasing to approximately zero; (2) linear elastic stage: it is observed that the curve of circumferential crack strain versus $\sigma_{1}-\sigma_{3}$ is approximately a straight line, corresponding to the end point of crack volume strain valued zero; (3) stable crack propagating stage: more cracks are initiating and propagating when the stress is greater than the crack initiation stress $\left(\sigma_{\mathrm{ci}}\right.$ is approximately $28.6 \%$ of peak stress $\sigma_{c}$ ), and corresponding volume strain reaches the maximum; (4) unstable crack developing stage 
TABLE 3: Permeability property and strength considering water pressure $2 \mathrm{MPa}$ and different confining pressure.

\begin{tabular}{lcccccccc}
\hline $\begin{array}{l}\text { Confining pressure } \\
(\mathrm{MPa})\end{array}$ & \multicolumn{2}{c}{$\begin{array}{c}\text { Initial permeability } \\
\left(10^{-18} \mathrm{~m}^{2}\right)\end{array}$} & $\begin{array}{c}\text { Minimum permeability } \\
\left(10^{-18} \mathrm{~m}^{2}\right)\end{array}$ & \multicolumn{2}{c}{$\begin{array}{c}\text { Maximum permeability } \\
\left(10^{-18} \mathrm{~m}^{2}\right)\end{array}$} & \multicolumn{2}{c}{$\begin{array}{c}\text { Peak strength } \\
(\mathrm{MPa})\end{array}$} \\
\hline 3 & Without mud & With mud & Without mud & With mud & Without mud & With mud & Without mud & With mud \\
\hline 6 & 84.94 & 47.20 & 76.76 & 30.24 & 414.62 & 176.20 & 52.43 & 21.60 \\
9 & 59.82 & 34.93 & 47.32 & 20.69 & 220.52 & 105.29 & 71.16 & 34.76 \\
15 & 44.12 & 22.94 & 32.68 & 12.33 & 176.96 & 40.63 & 86.20 & 45.24 \\
\hline
\end{tabular}

when the stress is greater than the damage stress $\left(\sigma_{\mathrm{cd}}\right.$ is approximately $66.2 \%$ of peak stress $\sigma_{c}$ ), the curve of strain versus $\sigma_{1}-\sigma_{3}$ is strongly nonlinear, and the crack volume stain increases much more representing crack propagating rapidly; (5) residual deformation stage: macrofractured surface appears with no new cracks initiation and propagation.

\subsection{Relationship between Permeability and Cracks Propaga-} tion for Two Kinds of Reservoir Sandstones. Figure 3 also describes the relationship between permeability and cracks propagation. It can be seen that the crack strain and the permeability almost have the same evolution under triaxial loading conditions, which means a direct relationship between the circumferential crack strain and the permeability of the sandstones. The permeability curve in the first stage corresponding to the strain-deviatoric stress curve decreases with the crack volume strain decreasing. Then the crack volume strain keeps zero in the second stage, so the permeability changes little. With the increase of load greater than the crack initiation stress $\sigma_{\mathrm{ci}}$ in the third stage, the permeability increases obviously until the volume strain reaches the maximum. Accordingly, the permeability increases dramatically in the fourth stage when the increase load exceeds the damage stress $\sigma_{\mathrm{cd}}$ and the crack volume strain reaches the maximum. Furthermore, the sandstone in the fifth stage may be continuously compressed in axial direction because of strain loading mode, resulting in decrease of the seepage channels; accordingly, the permeability decreases and becomes constant. Therefore, it can be obviously noted from Figure 3 that the permeability changes more intensely in crack damage region than in crack closure region, and the evolution process is precisely in accordance with the crack propagation.

For the sake of better describing the relationship between permeability and the cracks propagation under triaxial loading conditions, the gradual damage process and permeability behavior of two reservoir sandstones (without mud and with mud) are compared as shown in Figures 4 and 5. Also plotted in Figure 4 are the permeability evolution curves of the sandstones under loads combination of water pressure of $2 \mathrm{MPa}$ and confining pressure of $3 \mathrm{MPa}, 6 \mathrm{MPa}, 9 \mathrm{MPa}$, and $15 \mathrm{MPa}$, showing that the variation patterns of mechanical response and permeability under different confining pressures are similar for two reservoir sandstones. However, it can also be observed from Figures 4(a) and 4(b) that the values of volumetric strain, axial strain, lateral strain, and circumferential crack strain are different for two kinds of reservoir sandstones under same loading conditions, and the sandstone with mud shows relatively larger strain, smaller damage stress, smaller peak strength, and smaller permeability, which means that the sandstone with mud containing mud content of $29.8 \%$ has a better ductility; accordingly, the permeability of the sandstone with mud is smaller than that without mud. The above variations and the comparisons of two reservoir sandstones are under the same loading conditions plotted in Figure 4(c) versus Figure 4(d), Figure 4(e) versus Figure 4(f), and Figure 4(g) versus Figure 4(h). Further researches are shown in Figure 5 considering combination loads of confining pressure of $6 \mathrm{MPa}(15 \mathrm{MPa})$ and water pressure of $3 \mathrm{MPa}$ and $4 \mathrm{MPa}$. It can also be seen from Figure 5 that the permeability is smaller for the sandstone with mud than that without mud, which is in accordance with the variation patterns in Figure 4. Therefore, the comparison of permeability evolution of two reservoir sandstones illustrates that mud components play an important role on the permeability behavior.

\section{Permeability Behavior of Reservoir Sandstone with Different Physical Properties}

It is can be observed from Table 3 and Figure 6 that the permeability evolution of two reservoir sandstones varying with different confining pressure is similar, and the permeability decreases slowly with the increase deviatoric stress; with increase of compression load, corresponding circumferential crack strain gradually increases, representing that the primary cracks grow to form the favorable fissures causing the permeability to increase sharply. It also can be seen that larger confining pressure will cause smaller permeability.

Meanwhile, compared with two reservoir sandstones listed in Table 3, difference is obvious for the initial permeability, maximum permeability, and minimum permeability between the sandstone without mud and with mud under the same loading condition, and corresponding value of the former is larger than the latter. In virtue of sandstone with mud containing the mud content of $29.8 \%$, the mud-like materials can be softened by the water to show smaller peak strength when saturated; corresponding original porosity will decrease so as to cause the permeability to be smaller than that of the sandstone without mud.

Furthermore, curve of axial strain-deviatoric stress and axial strain-permeability is shown in Figure 6. The experimental results indicate that confining pressure significantly 


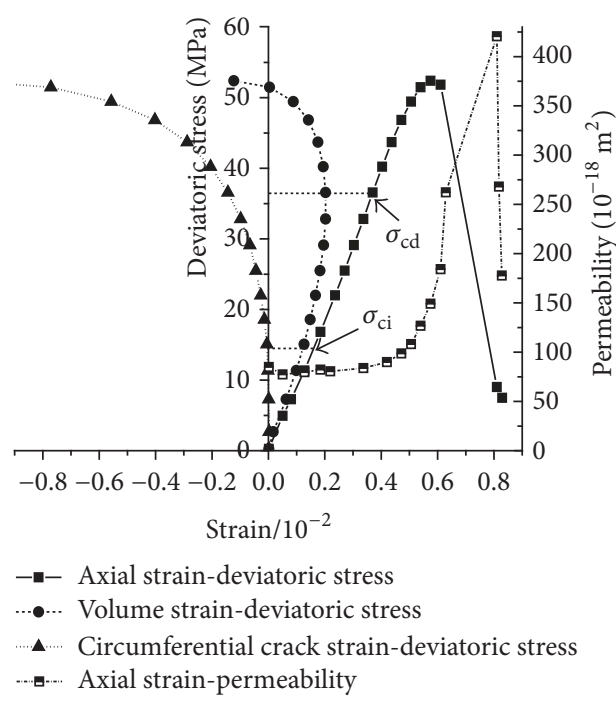

(a) Sandstone without mud (confining pressure $3 \mathrm{MPa}$ )

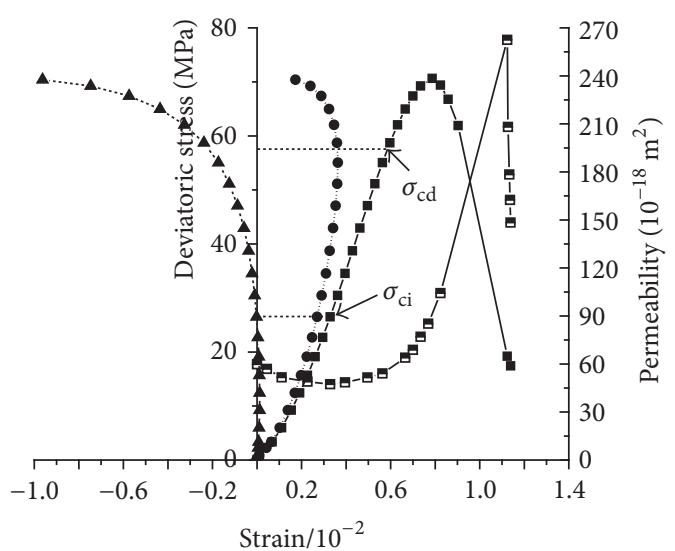

- - Axial strain-deviatoric stress

-... Volume strain-deviatoric stress

....... Circumferential crack strain-deviatoric stress

$\rightarrow-$ Axial strain-permeability

(c) Sandstone without mud (confining pressure $6 \mathrm{MPa}$ )

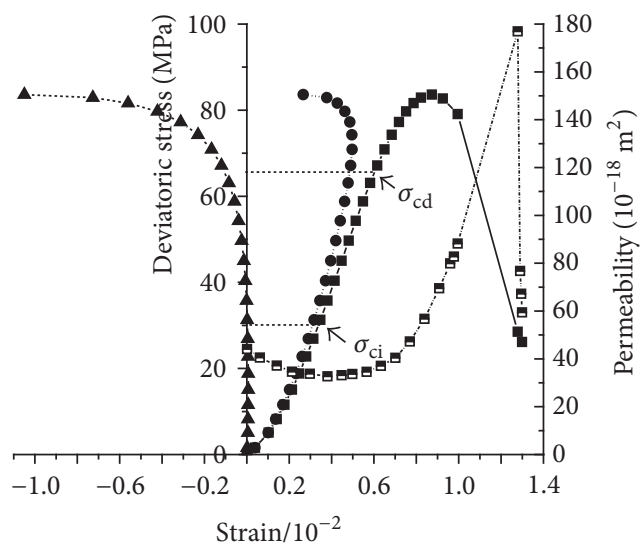

- - Axial strain-deviatoric stress

-... Volume strain-deviatoric stress

....... Circumferential crack strain-deviatoric stress

........ Axial strain-permeability

(e) Sandstone without mud (confining pressure 9 $\mathrm{MPa}$ )

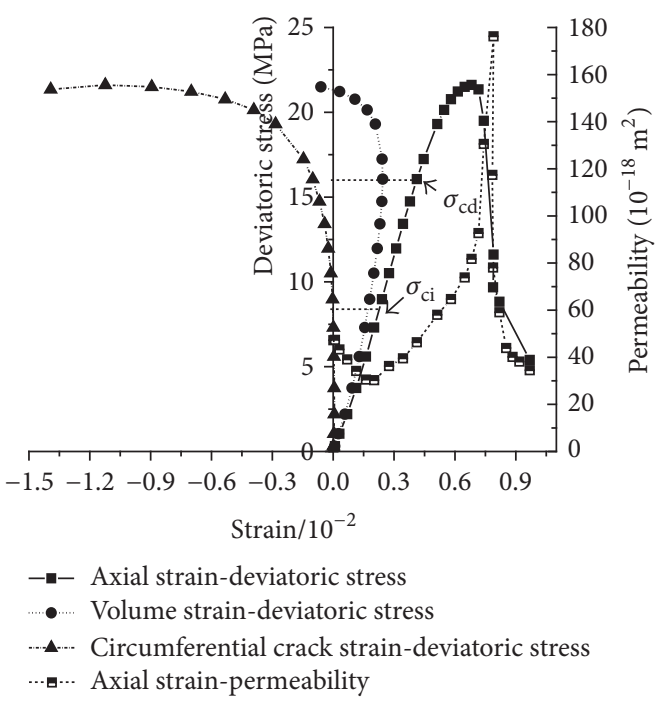

(b) Sandstone with mud (confining pressure $3 \mathrm{MPa}$ )

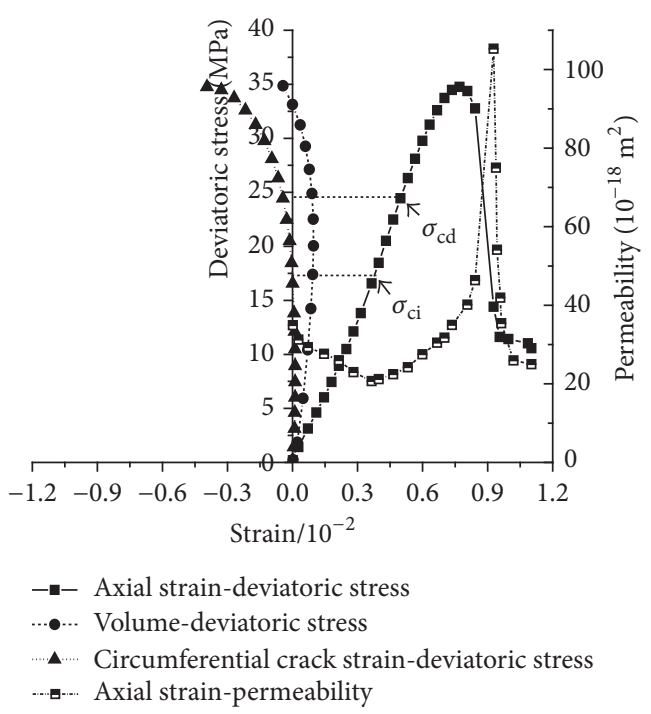

(d) Sandstone with mud (confining pressure $6 \mathrm{MPa}$ )

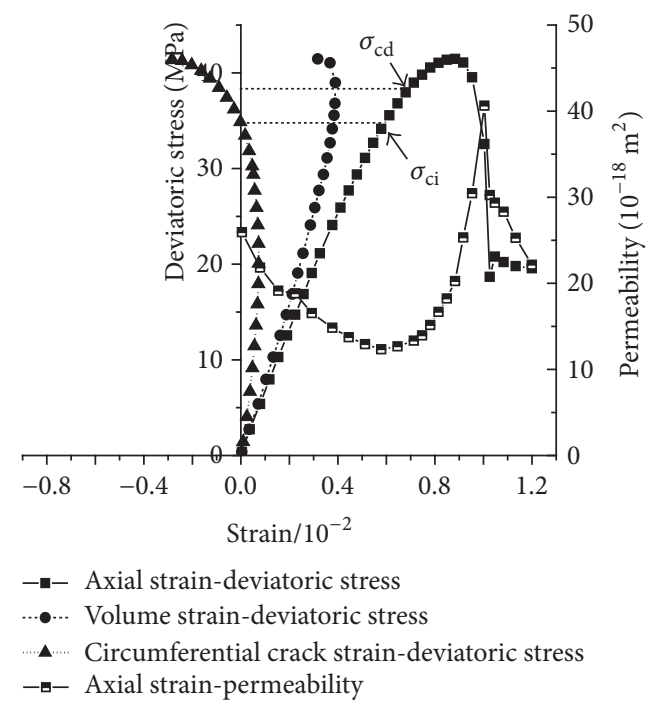

(f) Sandstone with mud (confining pressure 9 MPa)

Figure 4: Continued. 


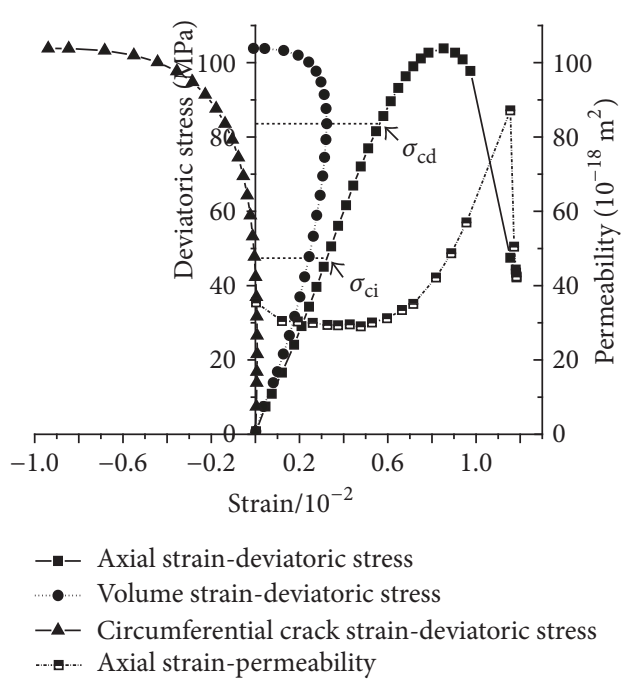

(g) Sandstone without mud (confining pressure $15 \mathrm{MPa}$ )

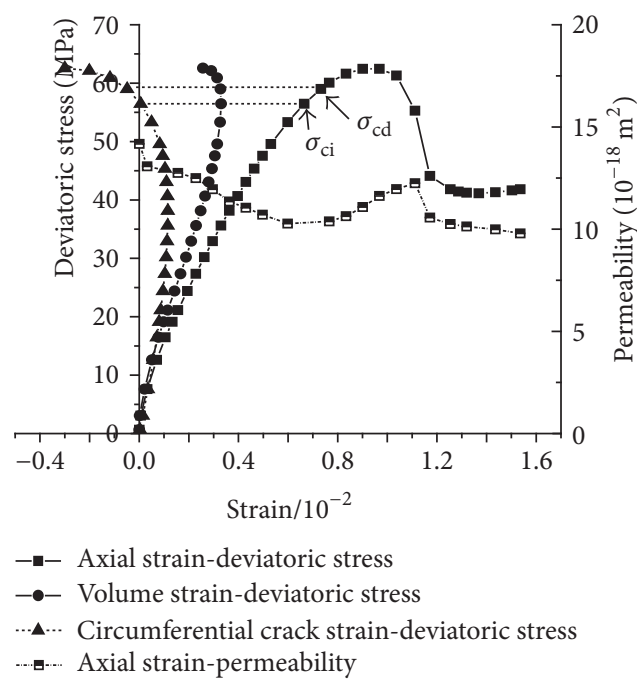

(h) Sandstone with mud (confining pressure $15 \mathrm{MPa}$ )

FIGURE 4: Gradual-cracking process and permeability behavior considering different confining pressure and water pressure valued $2 \mathrm{MPa}$.

TABLE 4: Permeability and strength considering confining pressure $6 \mathrm{MPa}$ and different water pressure.

\begin{tabular}{lcccccccc}
\hline $\begin{array}{l}\text { Permeable pressure } \\
(\mathrm{MPa})\end{array}$ & $\begin{array}{c}\text { Initial permeability } \\
\left(10^{-18} \mathrm{~m}^{2}\right)\end{array}$ & $\begin{array}{c}\text { Minimum permeability } \\
\left(10^{-18} \mathrm{~m}^{2}\right)\end{array}$ & \multicolumn{2}{c}{$\begin{array}{c}\text { Maximum permeability } \\
\left(10^{-18} \mathrm{~m}^{2}\right)\end{array}$} & \multicolumn{2}{c}{ Peak strength (MPa) } \\
& Without mud & With mud & Without mud & With mud & Without mud & With mud & Without mud & With mud \\
\hline 2 & 59.82 & 34.93 & 47.32 & 20.69 & 220.52 & 105.29 & 71.76 & 34.76 \\
3 & 73.66 & 44.83 & 58.02 & 33.40 & 236.94 & 152.49 & 68.10 & 34.73 \\
4 & 79.98 & 55.18 & 67.48 & 50.85 & 261.38 & 161.84 & 62.90 & 38.04 \\
\hline
\end{tabular}

influences the rock permeability under the same water pressure condition; as for the curve rising stage, larger confining pressure increases the compression of the rocks resulting in smaller permeability, and, especially for the sandstone with mud, the permeability curve is approximately a horizontal line and represents a much smaller value than that without mud, implying that mud components have an obvious impact on the mechanical properties and permeability of sandstone under larger confining pressure.

To analyze the influence of water pressure on the permeability evolution law of two sandstones, three different water pressures valued $2 \mathrm{MPa}, 3 \mathrm{MPa}$, and $4 \mathrm{MPa}$ combined with confining pressure valued $6 \mathrm{MPa}(15 \mathrm{MPa})$ are selected to the seepage tests. The initial permeability, minimum permeability, and maximum permeability of two sandstones without mud and with mud are listed in Tables 4 and 5. It is noted from Table 4 that initial permeability, minimum permeability, and maximum permeability of sandstone without mud are greater than that of the sandstone with mud, as well as the permeability listed in Table 5, indicating that mud-like materials have an important influence on the rock permeability; accordingly, the permeability is relatively smaller under the same loading conditions; especially difference of the maximum permeability between two reservoir sandstones is the greatest due to the existing mud component.
Furthermore, it can be seen from two tables describing the initial permeability, minimum permeability, and maximum permeability of two reservoir sandstones that greater water pressure considering the same confining pressure causes larger permeability; the main reason is that smaller effective stress is favorable for cracking to form more seepage channels, indicating that larger water pressure will expand the cracks more obviously to form connected and wider seepage channels resulting in larger permeability. Therefore, it is worth pointing out that water pressure significantly influences the rock permeability for sandstones without mud and with mud; the results also indicate that the rock components cannot be ignored and should be paid more attention when analyzing the permeability behavior for the sandstones with mud and without mud.

In addition, the permeability evolution under different combination of confining pressure and different water pressure are plotted in Figure 7. It can be seen from figures that permeability firstly decreases, keeps constant, increases stably, then increases dramatically, and finally decreases, which is in accordance with stress-strain curves representing five mechanical stages, deeply calibrating the synchronism of the permeability evolution with the crack initiation and propagation. And also, comparison of Figures 7(a) and 7(b) under combination of water pressure valued $2 \mathrm{MPa}, 3 \mathrm{MPa}$, and 


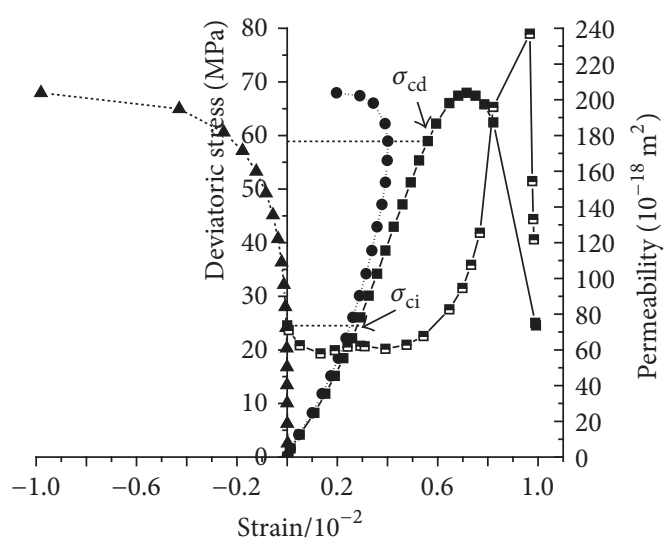

- Axial strain-deviatoric stress

•..... Volume strain-deviatoric stress

-.... Circumferential crack strain-deviatoric stress

-a- Axial strain-permeability

(a) Sandstone without mud (water pressure $3 \mathrm{MPa}+$ confining pressure $6 \mathrm{MPa}$ )

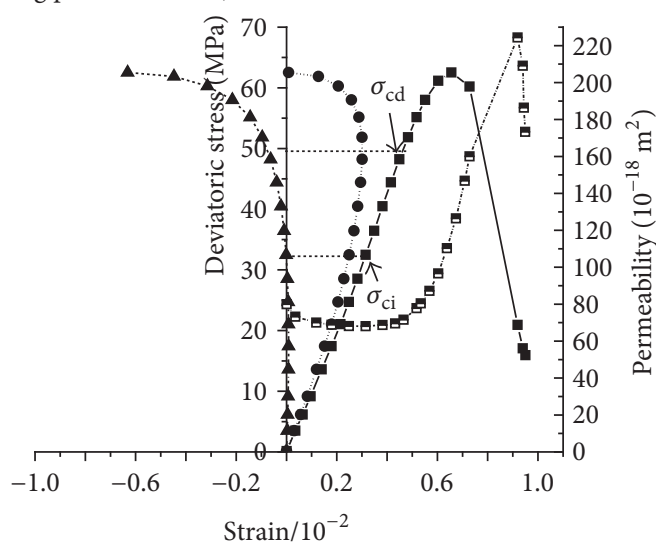

Strain $/ 10^{-2}$

- Axial strain-deviatoric stress

-... Volume strain-deviatoric stress

...... Circumferential crack strain-deviatoric stress

....... Axial strain-permeability

(c) Sandstone without mud (water pressure $4 \mathrm{MPa}+$ confining pressure $6 \mathrm{MPa}$ )

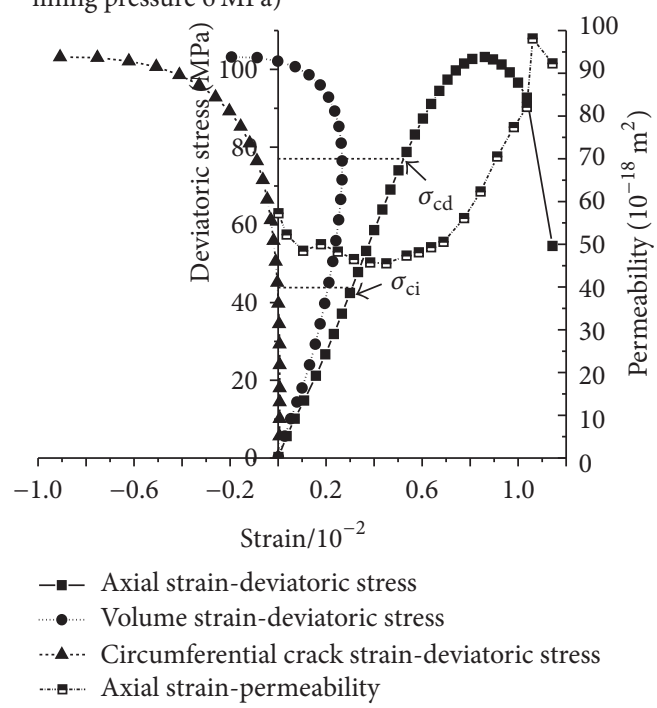

(e) Sandstone without mud (water pressure $3 \mathrm{MPa}+$ confining pressure $15 \mathrm{MPa}$ )

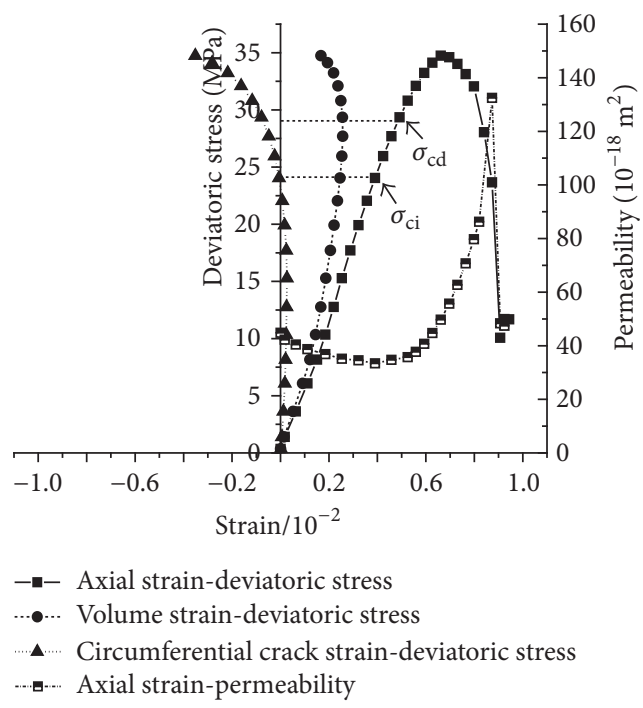

(b) Sandstone with mud (water pressure $3 \mathrm{MPa}+$ confining pressure $6 \mathrm{MPa}$ )

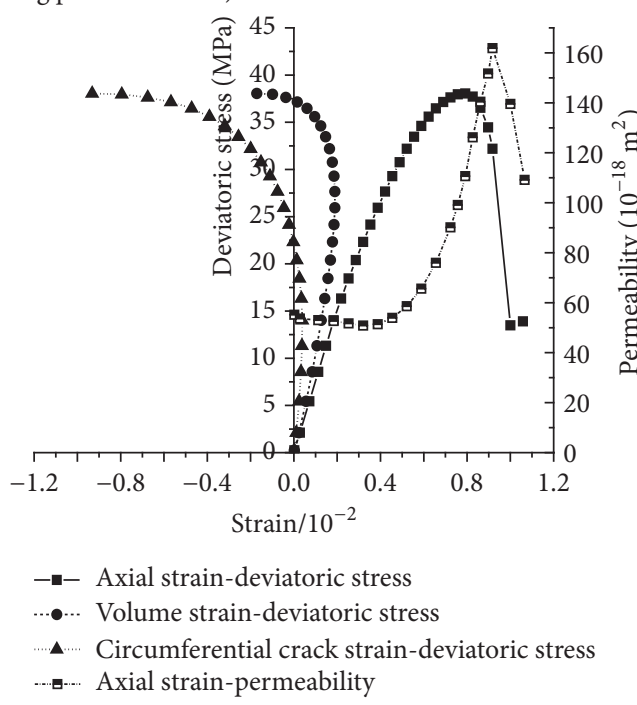

(d) Sandstone with mud (water pressure $4 \mathrm{MPa}+$ confining pressure $6 \mathrm{MPa}$ )

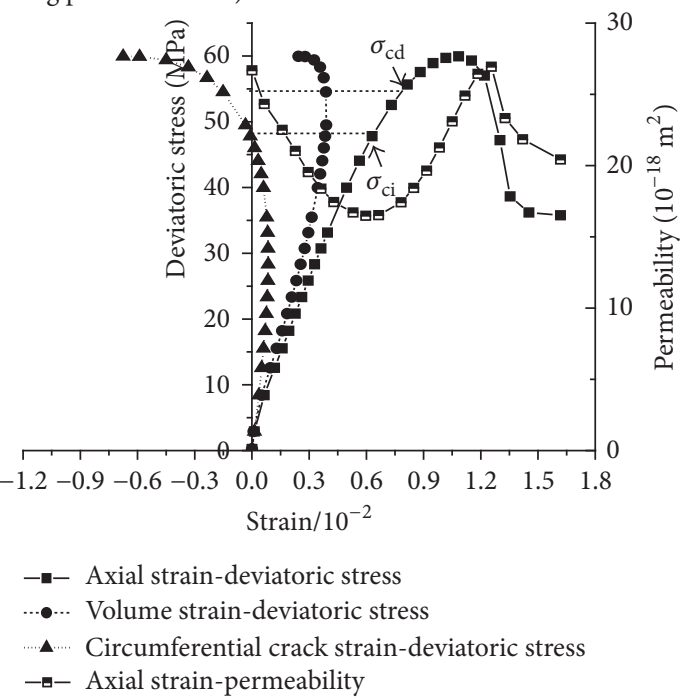

(f) Sandstone with mud (water pressure $3 \mathrm{MPa}+$ confining pressure $15 \mathrm{MPa}$ )

Figure 5: Continued. 


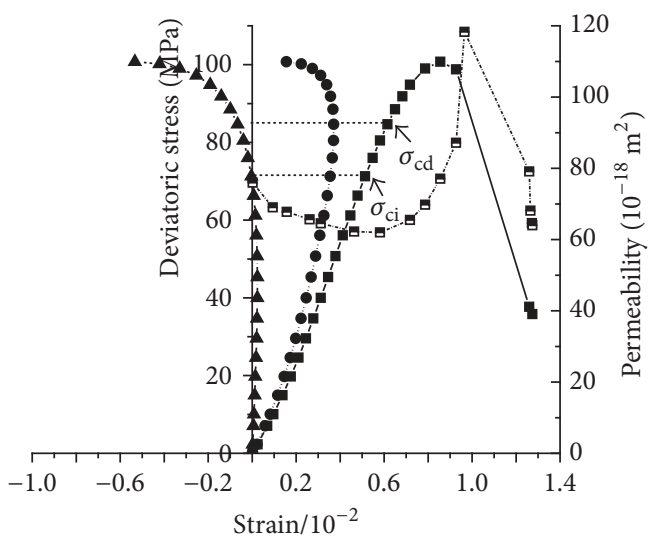

- Axial strain-deviatoric stress

-..... Volume strain-deviatoric stress

....... Circumferential crack strain-deviatoric stress

.......... Axial strain-permeability

(g) Sandstone without mud (water pressure $4 \mathrm{MPa}+$ confining pressure $15 \mathrm{MPa}$ )

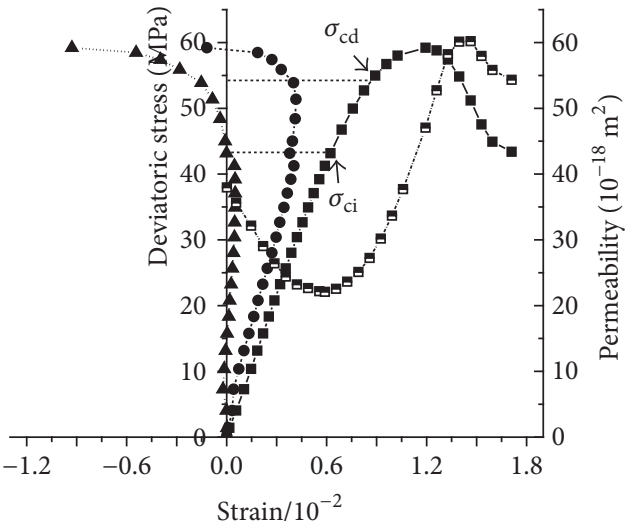

Axial strain-deviatoric stress

-... Volume strain-deviatoric stress

....... Circumferential crack strain-deviatoric stress

.......... Axial strain-permeability

(h) Sandstone with mud (water pressure $4 \mathrm{MPa}+$ confining pressure $15 \mathrm{MPa}$ )

FIGURE 5: Gradual-cracking process and permeability behavior considering different confining pressure and water pressure.

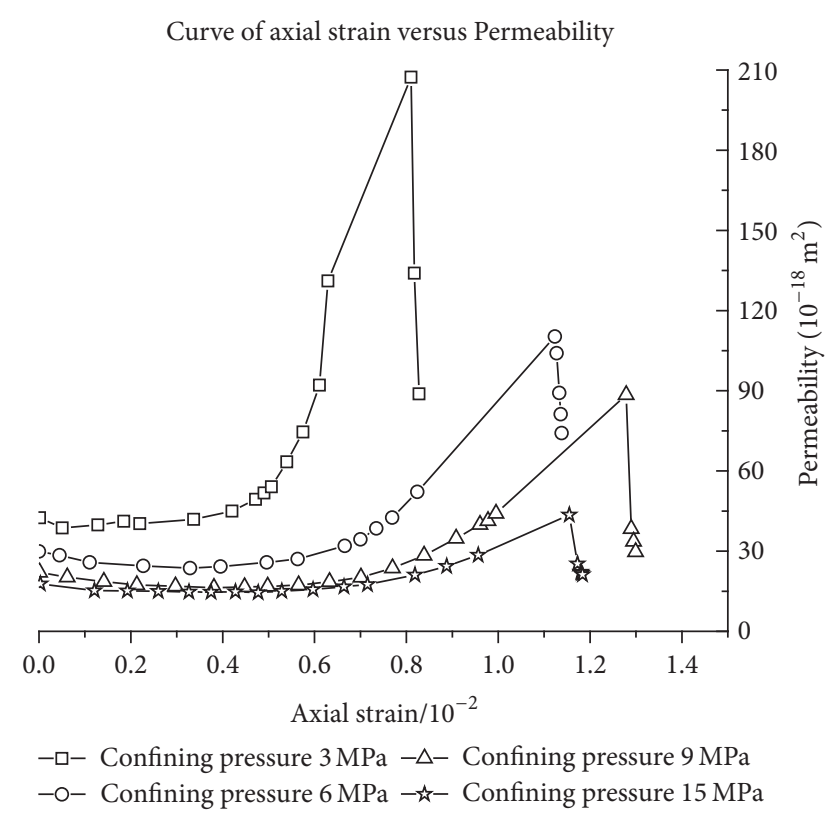

(a) Sandstone without mud
Curve of axial strain versus permeability

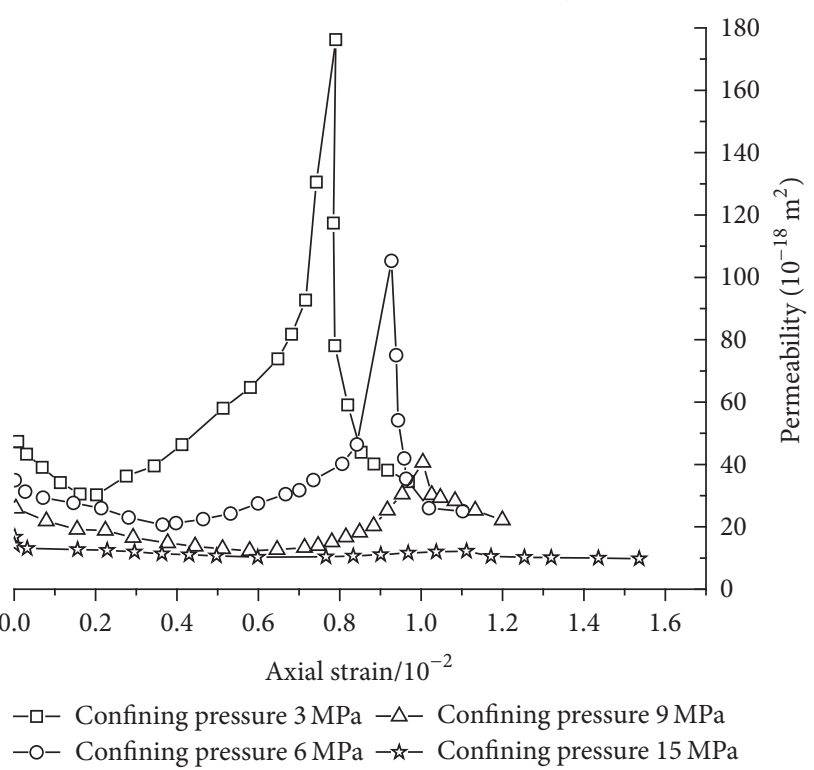

(b) Sandstone with mud

FIgURE 6: Permeability evolution of two reservoir sandstones considering water pressure $2 \mathrm{MPa}$ and different confining pressure.

TABLE 5: Permeability and strength considering confining pressure $15 \mathrm{MPa}$ and different water pressure.

\begin{tabular}{|c|c|c|c|c|c|c|c|c|}
\hline \multirow{2}{*}{$\begin{array}{l}\text { Permeable pressure } \\
(\mathrm{MPa})\end{array}$} & \multicolumn{2}{|c|}{$\begin{array}{l}\text { Initial permeability } \\
\quad\left(10^{-18} \mathrm{~m}^{2}\right)\end{array}$} & \multicolumn{2}{|c|}{$\begin{array}{l}\text { Minimum permeability } \\
\left(10^{-18} \mathrm{~m}^{2}\right)\end{array}$} & \multicolumn{2}{|c|}{$\begin{array}{l}\text { Maximum permeability } \\
\qquad\left(10^{-18} \mathrm{~m}^{2}\right)\end{array}$} & \multicolumn{2}{|c|}{ Peak strength $(\mathrm{MPa})$} \\
\hline & Without mud & With mud & Without mud & With mud & Without mud & With mud & Without mud & With mud \\
\hline 2 & 36.22 & 14.16 & 24.98 & 10.27 & 74.9 & 12.24 & 103.32 & 62.44 \\
\hline 3 & 57.22 & 26.68 & 45.52 & 16.48 & 109.74 & 26.93 & 103.19 & 59.93 \\
\hline 4 & 75.94 & 37.96 & 61.94 & 22.08 & 119.56 & 60.19 & 100.75 & 59.20 \\
\hline
\end{tabular}




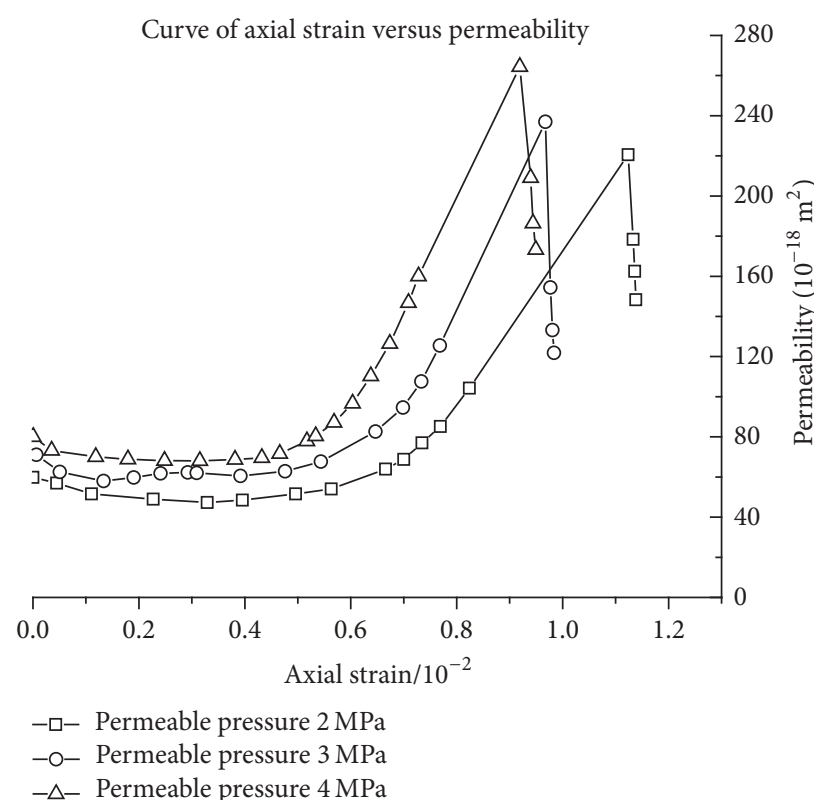

(a) Sandstone without mud under confining pressure $6 \mathrm{MPa}$

Curve of axial strain versus permeability

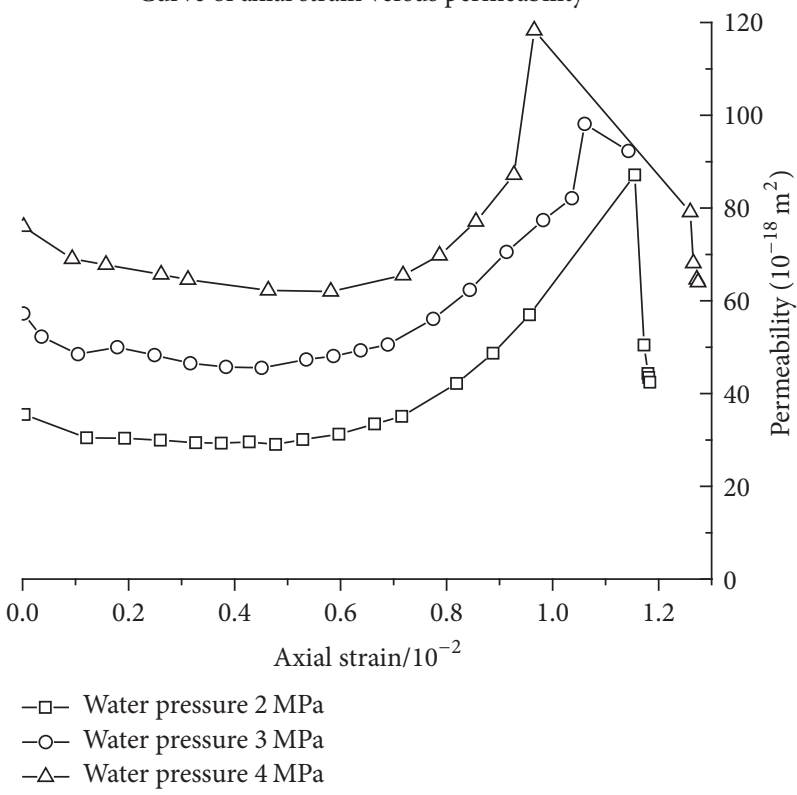

(c) Sandstone without mud under confining pressure $15 \mathrm{MPa}$

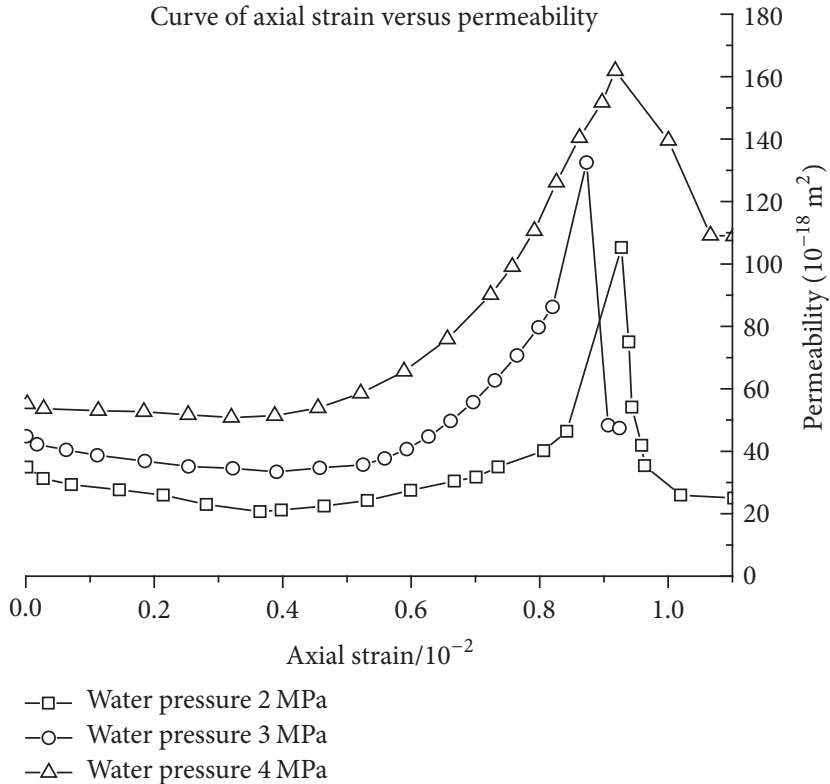

(b) Sandstone with mud under confining pressure $6 \mathrm{MPa}$

Curve of axial strain versus permeabitliy

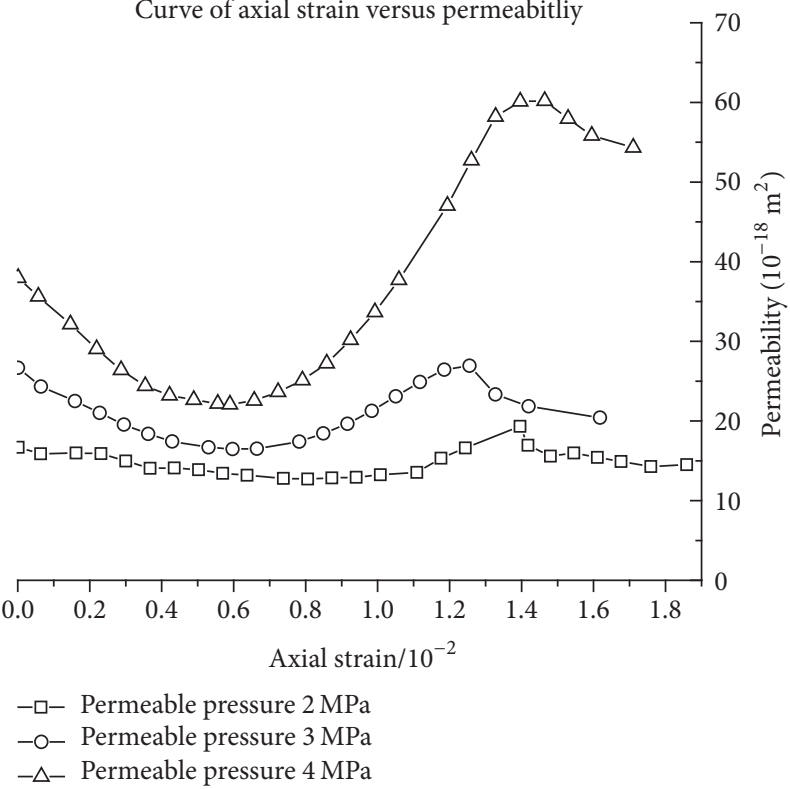

(d) Sandstone with mud under confining pressure $15 \mathrm{MPa}$

FIGURE 7: Permeability evolution of two sandstones considering different permeable pressure and confining pressure.

$4 \mathrm{MPa}$ and confining pressure valued $6 \mathrm{MPa}$ indicates that permeability is larger considering larger water pressure causing smaller effective stress to expand the cracks for two reservoir sandstones, as well as the permeability variation shown in Figures 7(c) and 7(d). However, the postpeak permeability curves of sandstone with mud are relatively smooth considering larger confining pressure combined smaller water pressure, indicating that corresponding permeability cannot change obviously because of larger effective stress.
According to above tests and analysis, larger water pressure applying on the rocks is favorable for rock hydraulic fracturing to accelerate the cracks initiating and propagating under same confining pressure conditions, and more connected seepage channels represent larger permeability beneficial for improvement of the reservoir recovery ratio; meanwhile, some measures should be taken to deal with mud-like materials when reservoir extracting so as to improve the reservoir permeability and productivity. 


\section{Permeability Evolution Mechanism of Reservoir Sandstones with Different Physical Properties}

5.1. Damage Theory. As evidenced by the experimental results in Sections 3 and 4, microcracks tend to develop and damage tends to grow in the rock samples under loading conditions, which induces significant variation in permeability. Souley et al. [24] and Oda et al. [25] mainly discussed the permeability variation induced by damage of granite under triaxial compression, and Chen et al. [26] also proposed a micromechanical model to describe the damage-induced permeability variation using the experimental data, which implies that rock damage discussion is very important for revealing the mechanism of permeability evolution. To deeply characterize the permeability change of reservoir rocks, an important index named damage variable $D$ describing the defects variation closely related to the microcrack growth and microstructural evolution should be proposed. Based on the research in the literature [27], it is assumed that the strength of rock microelements obeys Weibull stochastic distribution; accordingly, the damage variable $D$ can be described by

$$
D=1-\exp \left[-\left(\frac{F}{F_{0}}\right)^{m}\right]
$$

where $m$ and $F_{0}$ are the Weibull parameters; $F$ is the random strength variables of rock microelements.

Suppose $F=f\left(\tilde{\sigma}^{\prime}\right)$, where $\tilde{\sigma}^{\prime}$ is the effective stress tensors, so the rock failure criteria can be written by

$$
F=f\left(\tilde{\sigma}^{\prime}\right)-k_{0}=0,
$$

in which $k_{0}$ is constant related to cohesion and friction angle considering the rock yielding; $F=f\left(\widetilde{\sigma}^{\prime}\right) \geq k_{0}$ represents the rock yielding or failing.

In this study, the rock failure criteria may be described based on Drucker-Prager criteria:

$$
\begin{aligned}
& F=\alpha \widetilde{I}_{1}^{\prime}+\sqrt{\tilde{J}_{2}^{\prime}} \\
& \alpha=\frac{\sin \varphi}{\sqrt{9+3 \sin ^{2} \varphi}},
\end{aligned}
$$

where $\varphi$ is the friction angle; $\widetilde{I}_{1}^{\prime}$ is first invariant of effective stress tensor expressed as (9); $\widetilde{J}_{2}^{\prime}$ is second invariant of effective stress tensor expressed as (10).

$$
\begin{aligned}
& \widetilde{I}_{1}^{\prime}=\widetilde{\sigma}_{1}^{\prime}+\widetilde{\sigma}_{2}^{\prime}+\widetilde{\sigma}_{3}^{\prime} \\
& \tilde{J}_{2}^{\prime}=\frac{1}{6}\left[\left(\tilde{\sigma}_{1}^{\prime}-\tilde{\sigma}_{2}^{\prime}\right)^{2}+\left(\tilde{\sigma}_{2}^{\prime}-\tilde{\sigma}_{3}^{\prime}\right)^{2}+\left(\tilde{\sigma}_{1}^{\prime}-\tilde{\sigma}_{3}^{\prime}\right)^{2}\right] \text {. }
\end{aligned}
$$

Supposing the stress-strain of rocks obeying the Generalized Hook's Law, the effective strain tensor can be written by

$$
\widetilde{\varepsilon}_{i j}^{\prime}=\frac{1+\mu}{E} \widetilde{\sigma}_{i j}^{\prime}-\frac{\mu}{E} \widetilde{\sigma}_{k k}^{\prime} \delta_{i j}
$$

where $E$ is the elastic module; $\mu$ is Possion's ratio.
So the principle stress-stain can be written by

$$
\widetilde{\varepsilon}_{1}^{\prime}=\frac{1}{E}\left[\widetilde{\sigma}_{1}^{\prime}-\mu\left(\widetilde{\sigma}_{2}^{\prime}+\widetilde{\sigma}_{3}^{\prime}\right)\right] \text {. }
$$

Considering $\sigma_{1}>\sigma_{2}=\sigma_{3}$ in triaxial tests and $\varepsilon_{1}=\widetilde{\varepsilon}^{\prime}{ }_{1}$ due to coordination deformation between the damaged rocks and undamaged rocks, substituting the expression $\widetilde{\sigma}_{i j}^{\prime}=\left(\sigma_{i j}-\right.$ $\left.p_{w} \delta_{i j}\right) /(1-D)$ into (12) gives the stress-strain relations under hydromechanical coupling conditions as follows:

$$
\sigma_{1}=E \varepsilon_{1}(1-D)+2 \mu \sigma_{3}+(1-2 \mu) p_{w} .
$$

Thus, (9) and (10) can be rewritten by

$$
\begin{aligned}
I_{1} & =\frac{\left(\sigma_{1}+2 \sigma_{3}-3 p_{w}\right) E \varepsilon_{1}}{\sigma_{1}-2 \mu \sigma+(1-2 \mu) p_{w}} \\
\sqrt{J_{2}} & =\frac{\left(\sigma_{1}-\sigma_{3}\right) E \varepsilon_{1}}{\sqrt{3}\left[\sigma_{1}-2 \mu \sigma_{3}+(2 \mu-1) p_{w}\right]} .
\end{aligned}
$$

In addition, the measured axial deviatoric stress $\sigma_{1 t}$ in the experimental process is described by (16). And real axial stain $\varepsilon_{1}$ should include the measured stain $\varepsilon_{1 t}$ and initial stain $\varepsilon_{10}$ shown in (17).

$$
\begin{gathered}
\sigma_{1 t}=\sigma_{1}-\sigma_{3} \\
\varepsilon_{1}=\varepsilon_{1 t}+\varepsilon_{10} .
\end{gathered}
$$

Substituting the expression (16) and (17) into (14) and (15) gives the stress-strain relations under hydromechanical coupling conditions as follows:

$$
\begin{aligned}
I_{1} & =\frac{\left(\sigma_{1}+3 \sigma_{3}-3 p_{w}\right)\left[E \varepsilon_{1}+(1-2 \mu)\left(\sigma_{3}-p_{w}\right)\right]}{\sigma_{1 t}+(1-2 \mu)\left(\sigma_{3}-p_{w}\right)} \\
\sqrt{J_{2}} & =\frac{\sigma_{1 t}\left[E \varepsilon_{1}+(1-2 \mu)\left(\sigma_{3}-p_{w}\right)\right]}{\sqrt{3}\left[\sigma_{1 t}+(1-2 \mu)\left(\sigma_{3}-p_{w}\right)\right]} .
\end{aligned}
$$

Combining of (6), (13) and (16) (18), the statistical damage constitutive model considering pore pressure can be written by

$$
\begin{aligned}
\sigma_{1 t}= & {\left[E \varepsilon_{1 t}+(1-2 \mu)\left(\sigma_{3}-p_{w}\right)\right] \exp \left[-\left(\frac{F}{F_{0}}\right)^{m}\right] } \\
& +(2 \mu-1)\left(\sigma_{3}-p_{w}\right),
\end{aligned}
$$

where

$$
\begin{aligned}
F= & \frac{\left[E \varepsilon_{1 t}+(1-2 \mu)\left(\sigma_{3}-p_{w}\right)\right]}{\sigma_{1 t}+(1-2 \mu)\left(\sigma_{3}-p_{w}\right)} \\
& \cdot\left[\frac{\sin \varphi\left(\sigma_{1 t}+3 \sigma_{3}-3 p_{w}\right)}{\left.\sqrt{9+3 \sin ^{2} \varphi}+\frac{\sigma_{1 t}}{\sqrt{3}}\right] ;}\right.
\end{aligned}
$$

$E$ is elastic module; $\varepsilon_{1 t}$ is deviatoric strain; $\sigma_{1 t}$ is deviatoric stress; $\sigma_{3}$ is confining pressure; $p_{w}$ is permeable pressure; $\varphi$ is 


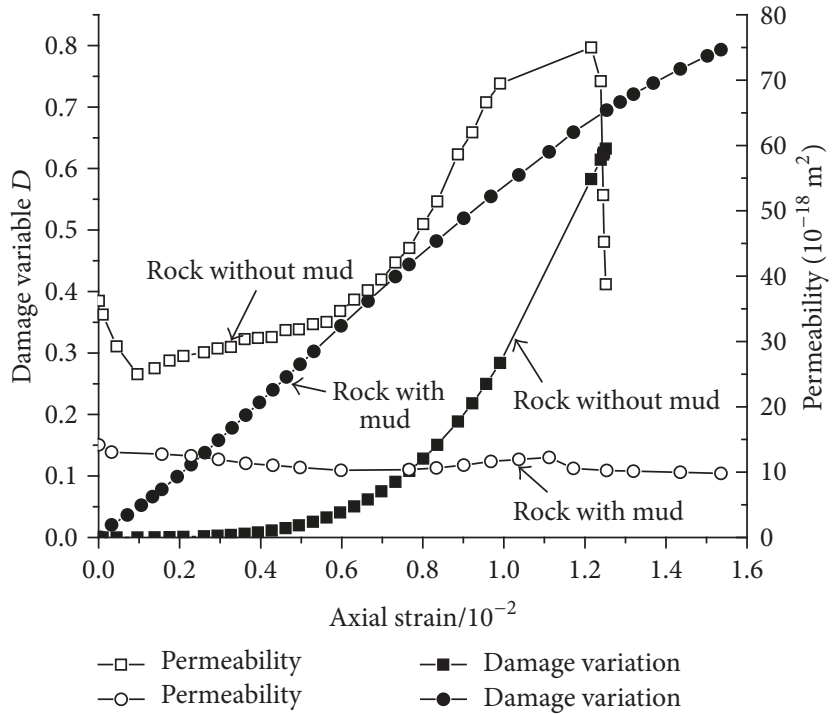

(a) Confining pressure $15 \mathrm{MPa}$ and water pressure $2 \mathrm{MPa}$

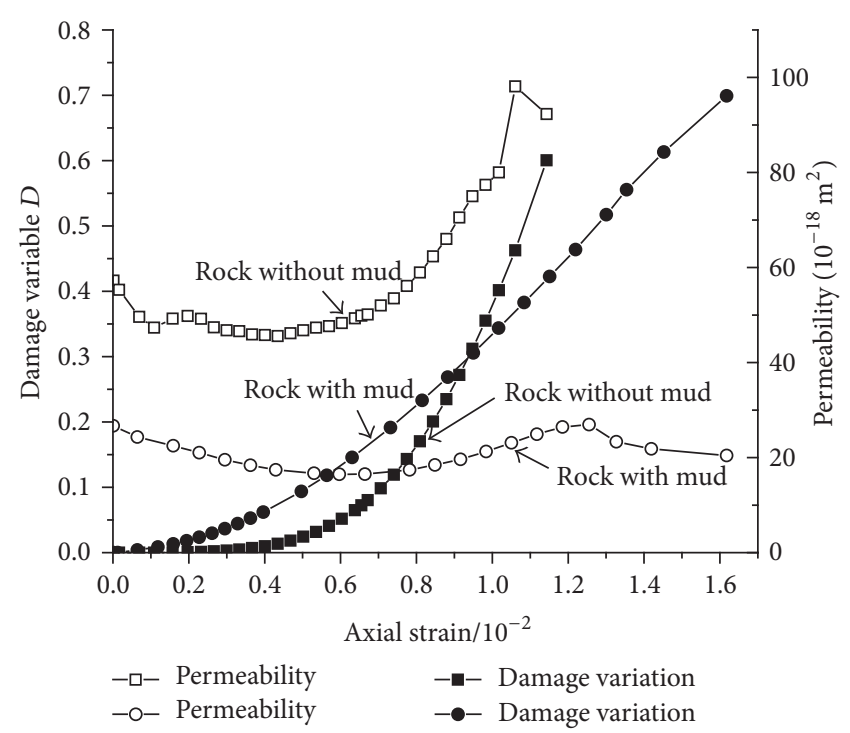

(b) Confining pressure $15 \mathrm{MPa}$ and water pressure $3 \mathrm{MPa}$

FIGURE 8: Damage and permeability variation induced by hydromechanical coupling effect.

internal frictional angle as $43.075^{\circ}$ for sandstone without mud and 27.29 for sandstone with mud; $\mu$ is Poisson's ratio, 0.19 for sandstone without mud and 0.3 for sandstone with mud.

And then, (19) may be changed as follows:

$$
\begin{aligned}
& \frac{\sigma_{1 t}-(2 \mu-1)\left(\sigma_{3}-P_{w}\right)}{E \varepsilon_{1 t}+(1-2 \mu)\left(\sigma_{3}-P_{w}\right)}=\exp \left(-\left(\frac{F}{F_{0}}\right)^{m}\right) \\
& \ln \left\{\ln \left[\frac{\sigma_{1 t}-(2 \mu-1)\left(\sigma_{3}-P_{w}\right)}{E \varepsilon_{1 t}+(1-2 \mu)\left(\sigma_{3}-P_{w}\right)}\right]\right\}=m \ln F-B,
\end{aligned}
$$

in which, $B$ is the fitting parameter.

Thus, $F_{0}$ can be calculated according to the fitting analysis:

$$
F_{0}=\exp \left(\frac{B}{m}\right)
$$

5.2. Evolution Mechanism of the Permeability. The damage variables of two sandstones during the whole loading process can be calculated based on above equations; the evolution of damage variables $D$ and permeability under combination of confining pressure $15 \mathrm{MPa}$ and permeable pressure $2 \mathrm{MPa}$ ( $3 \mathrm{MPa}$ ) are shown in Figures $8(\mathrm{a})$ and $8(\mathrm{~b})$. It can be observed from the figures that $D$ variation is basically similar to keep ascending, but significant difference of the permeability is very obvious in numerical value between two sandstones. And comparison of Figures 8(a) and 8(b) also indicates larger water pressure resulting in smaller $D$ under same confining pressure; corresponding maximum $D$ decreasing implies that larger water pressure can accelerate the sandstone damage to fail more easily.

Furthermore, it can be seen from Figure 8 that the variation of $D$ is in accordance with the damage-induced permeability variation of sandstone without mud in the loading process, with a decrease in the initial inelastic region, an almost constant in the elastic region and dramatic increase in the crack growth region, implying that deviatoric stress causes the pores and cracks to be compressed firstly, keep unchangeable, and finally sharply increase because of higher strength and stronger cohesion for this type of sandstone. However, different from the variation of $D$ for the sandstone without mud, the damage variables $D$ increase stably, implying that the pores and cracks inside the sandstone with mud should be more greatly compressed when applying the confining pressure, and the pores and cracks will be more dramatically compressed even under smaller deviatoric stress conditions; thus the pores may probably be collapsed and the mud-like materials will slide to cause the damage develop stably. In addition, the maximum $D$ for the sandstone with mud is larger than that for the sandstone without mud, indicating that sandstone without mud is more brittle than the sandstone with mud increasing the sandstone ductility.

In addition, to better investigate the permeability evolution induced by rock damage causing the crack propagation, the relationship of the permeability and damage variable $D$ can be established and analyzed. Based on the experimental data, the relationship between damage variable $D$ and circumferential crack strain $\varepsilon_{c 3}$ can be described by (23), which is another expression of damage variable $D$, providing a new way to describe the permeability variation.

$$
D=\ln \left(a_{1}+b_{1} * \varepsilon_{c 3}\right) \text {, }
$$

where $D$ is damage variable; $a_{1}, b_{1}$ is the fitting parameters based on experimental data.

And then, the damage variable $D$ related to the circumferential crack strain $\varepsilon_{c 3}$ under confining pressure of $15 \mathrm{MPa}$ and water pressure of $2 \mathrm{MPa}$ can be shown in Figures 9(a) and 9 (b) and also is calibrated for the combination loads of confining pressure of $15 \mathrm{MPa}$ and water pressure of $3 \mathrm{MPa}$. The results show that damage variable $D$ is logarithmic relation to the circumferential crack strain $\varepsilon_{c 3}$, and the correlation 


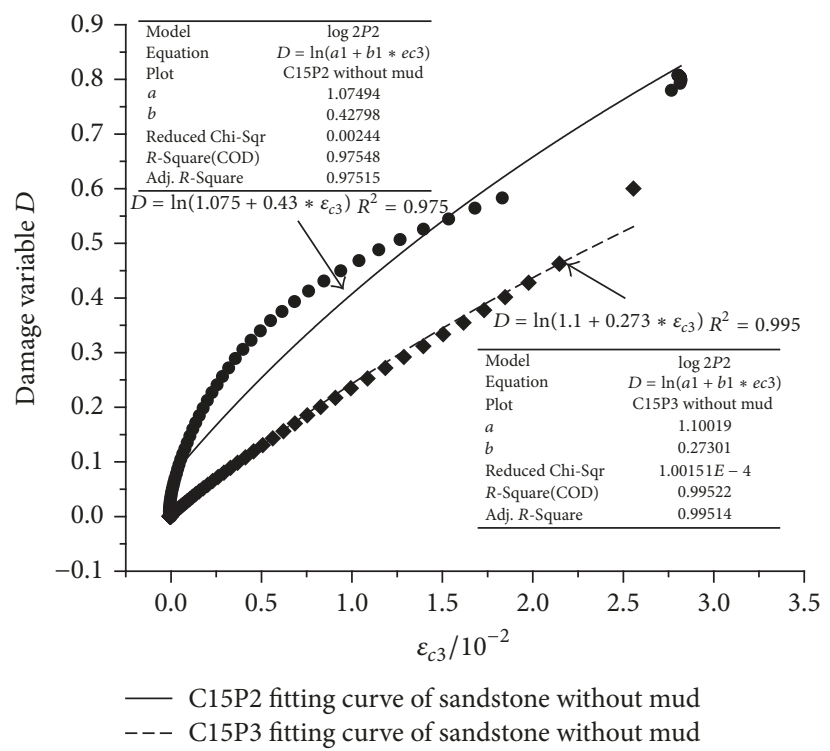

(a) Sandstone without mud

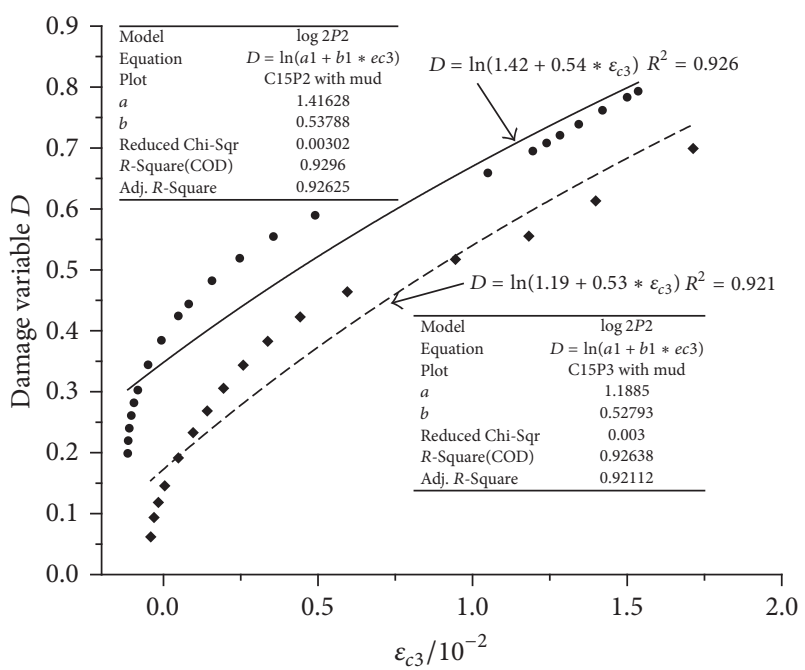

- C15P2 fitting curve of sandstone with mud --- C15P3 fitting curve of sandstone with mud

(b) Sandstone with mud

FIGURE 9: The relationship of damage variable and circumferential crack strain.

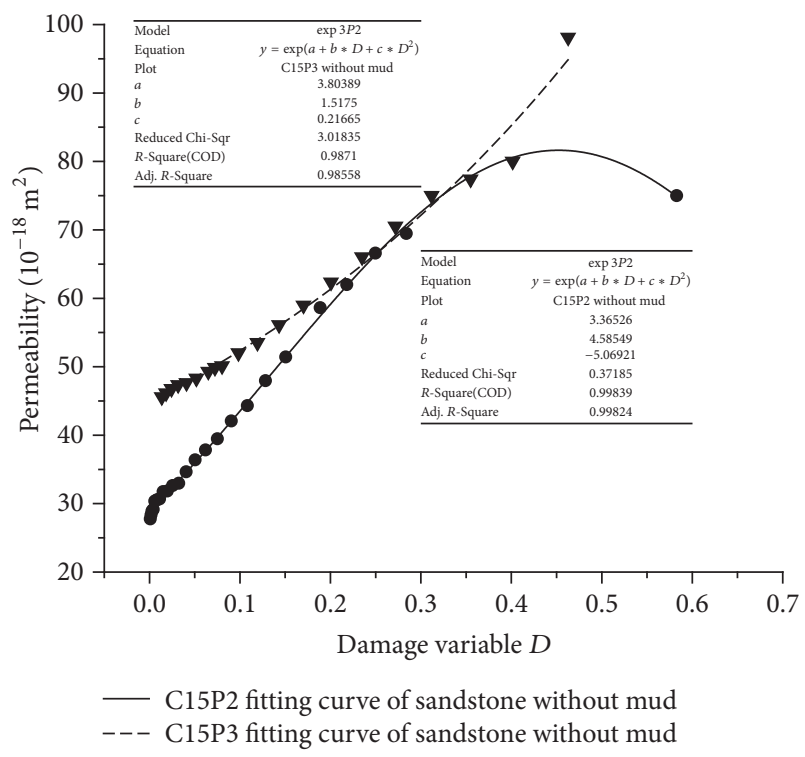

(a) Sandstone without mud

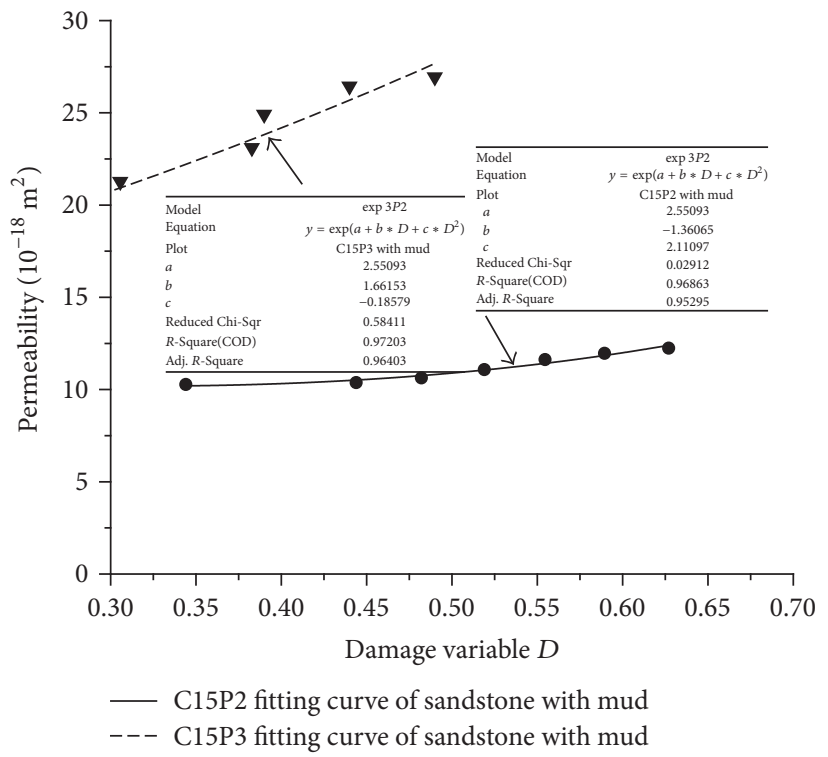

(b) Sandstone with mud

FIGURE 10: The relationship of the permeability and damage variation.

coefficients $R^{2}$ are, respectively, greater than 0.92 and 0.975 , indicating that rock damage variable $D$ also represents the variation of crack strain. Thus, the permeability related to the damage variable $D$ can be written by (24) using the testing data under confining pressure of $15 \mathrm{MPa}$ and water pressure of $2 \mathrm{MPa}$, shown in Figures 10(a) and 10(b).

$$
K=\zeta \exp \left(a+b D+c D^{2}\right),
$$

where $K$ is the permeability; $D$ is damage variable; $\zeta$ is a parameter valued $10^{-18} ; a, b, c$ is the fitting parameters based on experimental data. For calibrating the rationality of the fitting equation (24), the curves of permeability under confining pressure of $15 \mathrm{MPa}$ and water pressure of $3 \mathrm{MPa}$ have been given in Figures 10(a) and 10(b), showing that correlation coefficients are greater than 0.95 , which also reveal the mechanism of permeability evolution based on damage variable or circumferential crack strain. Furthermore, the comparisons deeply illustrate that damage is more obvious causing larger permeability for the sandstone without mud.

The evolution law of two different sandstones deeply explains the reason of more rapid increase of permeability 
and larger permeability for the sandstone without mud than that with mud under same loading conditions, revealing the evolution mechanism of permeability and indicating that the rock components greatly influence the permeability behavior, which is very useful to provide a theoretical suggestion for the effective development of sandstone reservoir.

\section{Conclusions}

In this study, triaxial compression tests have been conducted for permeability measurement of reservoir sandstones without mud and with mud under combination of different confining pressure and water pressure. Meanwhile, the mechanism involved in the permeability variation has been analyzed and compared; especially a damage mechanical model has been employed to deeply investigate the permeability evolution between two reservoir sandstones. Based on the experimental results, the following conclusions can be concluded:

(1) The variations in permeability of reservoir sandstones with confining pressure and water pressure have been demonstrated. Corresponding to the distinct features in the strain-stress curves, the permeability curves in five stages also exhibit a clear permeability decrease, constant, stable increase, and sharp increase and decrease. As the deviatoric stress increases up to the specimen failure, the permeability increases up to the maximum. With increase of confining pressures, on the other hand, the permeability reduces due to more significant closure of existing microcracks. And also the comparison under same loading conditions explains that permeability is larger for the sandstone without mud because of better brittleness.

(2) The variation patterns of permeability for reservoir sandstones under loads combination are similar although the confining pressure and water pressure have a great influence on the permeability value. However, the strength and permeability are smaller for the sandstone with mud than that without mud, deeply indicating the mud-like materials also have a relatively great impact on the mechanical property and permeability; thus mud components cannot be ignored in analysis of the reservoir development.

(3) The damage analysis has been employed based on the statistical damage constitutive model to investigate the relationship of rock damage evolution and permeability, also indicating that larger water pressure results in a relatively smaller damage variables $D$ and corresponding maximum under same confining pressure, which explains why the permeability increases more rapidly and larger for the sandstone without mud than that with mud. And also, the damage variable may represent the circumferential crack strain, and the relationship of the permeability and damage variable $D$ implies the evolution mechanism of permeability for two sandstones with different properties.

\section{Conflicts of Interest}

The authors declare that there are no conflicts of interest regarding the publication of this paper.

\section{Authors' Contributions}

Ming Xu and Xianshan Liu equally contributed to this work.

\section{Acknowledgments}

The research is financially supported by the National Natural Science Foundation of China, nos. 51779021 and 51478065, and the Fund of National Engineering and Research Center for Mountainous Highways no. GSGZJ-2015-09.

\section{References}

[1] T. Han, A. I. Best, J. Sothcott, L. J. North, and L. M. MacGregor, "Relationships among low frequency $(2 \mathrm{~Hz})$ electrical resistivity, porosity, clay content and permeability in reservoir sandstones," Journal of Applied Geophysics, vol. 112, pp. 279-289, 2015.

[2] Y. Xiong, H. Xu, Y. Wang, W. Zhou, L. Wang, and K. Feng, "The variation mechanism of petrophysical properties and the effect of compaction on the relative permeability of an unconsolidated sandstone reservoir," Marine and Petroleum Geology, 2017.

[3] L. K. Ma, J. Wang, X. G. Zhao et al., "Experimental study on permeability of Beishan granite," in Rock Mechanics: Achievements and Ambitions, pp. 173-176, Talyor and Francis Group, London, UK, 2012.

[4] A. K. M. B. Alam, M. Niioka, Y. Fujii, D. Fukuda, and J.-I. Kodama, "Effects of confining pressure on the permeability of three rock types under compression," International Journal of Rock Mechanics and Mining Sciences, vol. 65, pp. 49-61, 2014.

[5] X. Tan, H. Konietzky, and T. Frühwirt, "Laboratory observation and numerical simulation of permeability evolution during progressive failure of brittle rocks," International Journal of Rock Mechanics and Mining Sciences, vol. 68, pp. 167-176, 2014.

[6] H. L. Wang and W. Y. Xu, "Permeability evolution laws and equations during the course of deformation and failure of brittle rock," Journal of Engineering Mechanics, vol. 139, no. 11, pp. 16211625, 2013.

[7] Z. Zeng, X. Li, L. Shi, B. Bai, Z. Fang, and Y. Wang, "Experimental study of the laws between the effective confining pressure and mudstone permeability," in Proceedings of the 12th International Conference on Greenhouse Gas Control Technologies, GHGT 2014, pp. 5654-5663, October 2014.

[8] C.-L. Zhang, "The stress-strain-permeability behaviour of clay rock during damage and recompaction," Journal of Rock Mechanics and Geotechnical Engineering, vol. 8, no. 1, pp. 16-26, 2016.

[9] H.-L. Wang, W.-J. Chu, and M. He, "Anisotropic permeability evolution model of rock in the process of deformation and failure," Journal of Hydrodynamics, vol. 24, no. 1, pp. 25-31, 2012.

[10] Q.-L. Ding, F. Ju, S.-B. Song, B.-Y. Yu, and D. Ma, "An experimental study of fractured sandstone permeability after hightemperature treatment under different confining pressures," Journal of Natural Gas Science and Engineering, vol. 34, pp. 5563, 2016.

[11] S.-Q. Yang, Y.-H. Huang, Y.-Y. Jiao, W. Zeng, and Q.-L. Yu, "An experimental study on seepage behavior of sandstone material 
with different gas pressures," Acta Mechanica Sinica, vol. 31, no. 6, pp. 837-844, 2015.

[12] N. Zisser and G. Nover, "Anisotropy of permeability and complex resistivity of tight sandstones subjected to hydrostatic pressure," Journal of Applied Geophysics, vol. 68, no. 3, pp. 356370, 2009.

[13] D. W. Hu, H. Zhou, F. Zhang, and J. F. Shao, "Evolution of poroelastic properties and permeability in damaged sandstone," International Journal of Rock Mechanics and Mining Sciences, vol. 47, no. 6, pp. 962-973, 2010.

[14] M. E. French, F. M. Chester, J. S. Chester, and J. E. Wilson, "Stress-dependent transport properties of fractured arkosic sandstone," Geofluids, vol. 16, no. 3, pp. 533-551, 2016.

[15] M. D. Ingrahama, S. J. Bauera, K. A. Issenb, and T. A. Dewers, "Evolution of permeability and Biot coefficient at high mean stresses in high porosity sandstone," International Journal of Rock Mechanics \& Mining Sciences, vol. 96, pp. 1-10, 2017.

[16] S.-Q. Yang, P. Xu, Y.-B. Li, and Y.-H. Huang, "Experimental investigation on triaxial mechanical and permeability behavior of sandstone after exposure to different high temperature treatments," Geothermics, vol. 69, pp. 93-109, 2017.

[17] D. Xiao, S. Jiang, D. Thul, S. Lu, L. Zhang, and B. Li, "Impacts of clay on pore structure, storage and percolation of tight sandstones from the Songliao Basin, China: Implications for genetic classification of tight sandstone reservoirs," Fuel, vol. 211, pp. 390-404, 2018.

[18] M. Li, G. Yin, J. Xu, J. Cao, and Z. Song, "Permeability evolution of shale under anisotropic true triaxial stress conditions," International Journal of Coal Geology, vol. 165, pp. 142-148, 2016.

[19] J.-J. Dong, J.-Y. Hsu, W.-J. Wu et al., "Stress-dependence of the permeability and porosity of sandstone and shale from TCDP Hole-A," International Journal of Rock Mechanics and Mining Sciences, vol. 47, no. 7, pp. 1141-1157, 2010.

[20] W. Wu, M. D. Zoback, and A. H. Kohli, "The impacts of effective stress and $\mathrm{CO} 2$ sorption on the matrix permeability of shale reservoir rocks," Fuel, vol. 203, pp. 179-186, 2017.

[21] J. Heiland, "Laboratory testing of coupled hydro-mechanical processes during rock deformation," Hydrogeology Journal, vol. 11, no. 1, pp. 122-141, 2003.

[22] C. D. Martin and N. A. Chandler, "The progressive fracture of Lac du Bonnet granite," International Journal of Rock Mechanics and Mining Sciences, vol. 31, no. 6, pp. 643-659, 1994.

[23] P. Xu and S.-Q. Yang, "Permeability evolution of sandstone under short-term and long-term triaxial compression," International Journal of Rock Mechanics and Mining Sciences, vol. 85, pp. 152-164, 2016.

[24] M. Souley, F. Homand, S. Pepa, and D. Hoxha, "Damageinduced permeability changes in granite: a case example at the URL in Canada," International Journal of Rock Mechanics and Mining Sciences, vol. 38, no. 2, pp. 297-310, 2001.

[25] M. Oda, T. Takemura, and T. Aoki, "Damage growth and permeability change in triaxial compression tests of Inada granite," Mechanics of Materials, vol. 34, no. 6, pp. 313-331, 2002.

[26] Y. Chen, S. Hu, K. Wei, R. Hu, C. Zhou, and L. Jing, "Experimental characterization and micromechanical modeling of damage-induced permeability variation in Beishan granite," International Journal of Rock Mechanics and Mining Sciences, vol. 71, pp. 64-76, 2014.

[27] C. Gao, L. Z. Xie, H. P. Xie et al., "Coupling between the statistical damage model and permeability variation in reservoir sandstone: Theoretical analysis and verification," Journal of Natural Gas Science and Engineering, vol. 37, pp. 375-385, 2017. 

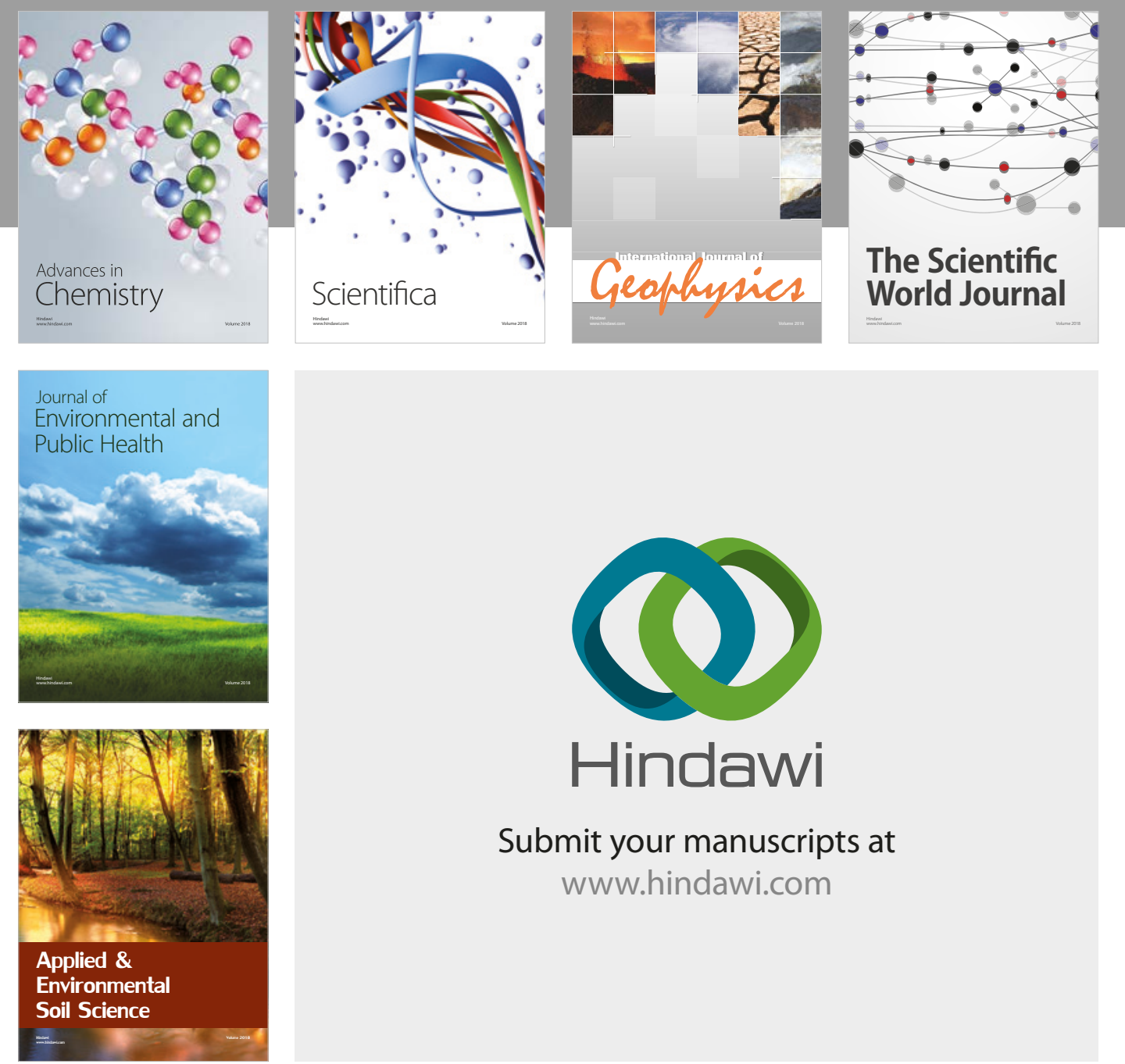

The Scientific

\section{World Journal}
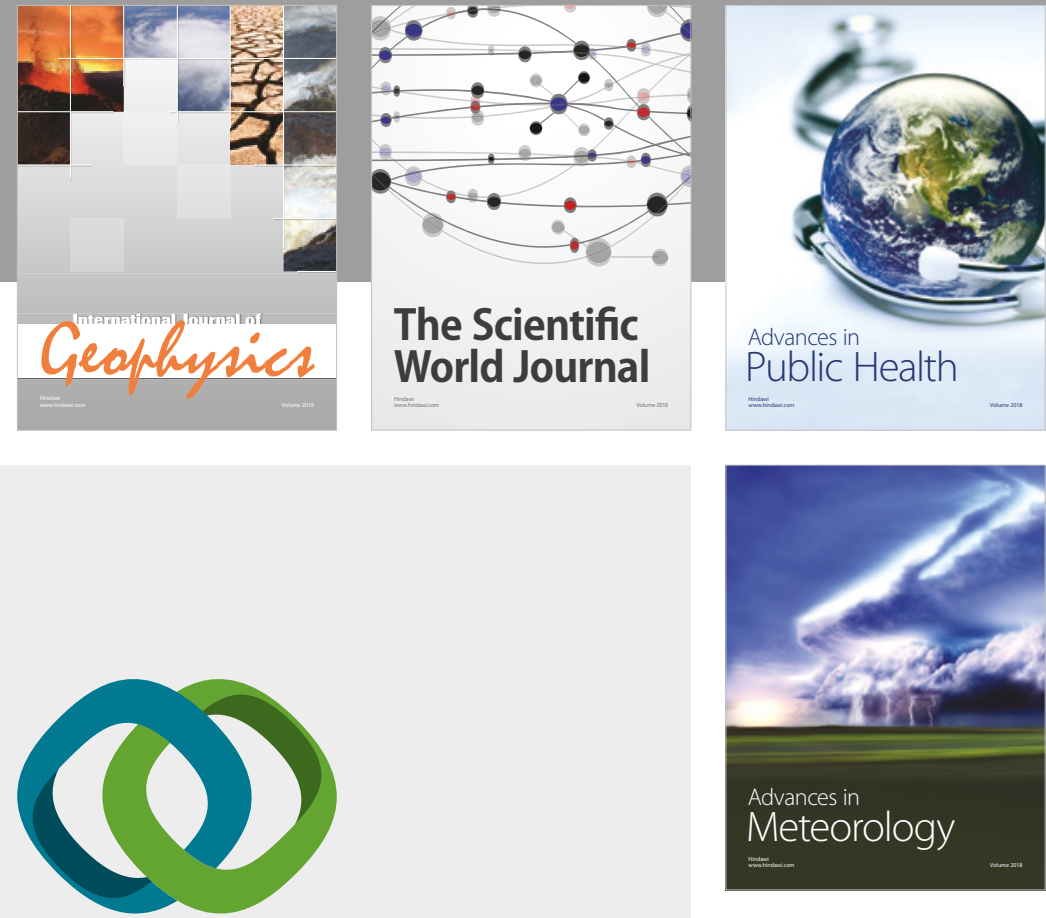

Advan

Public Health

\section{Hindawi}

Submit your manuscripts at

www.hindawi.com
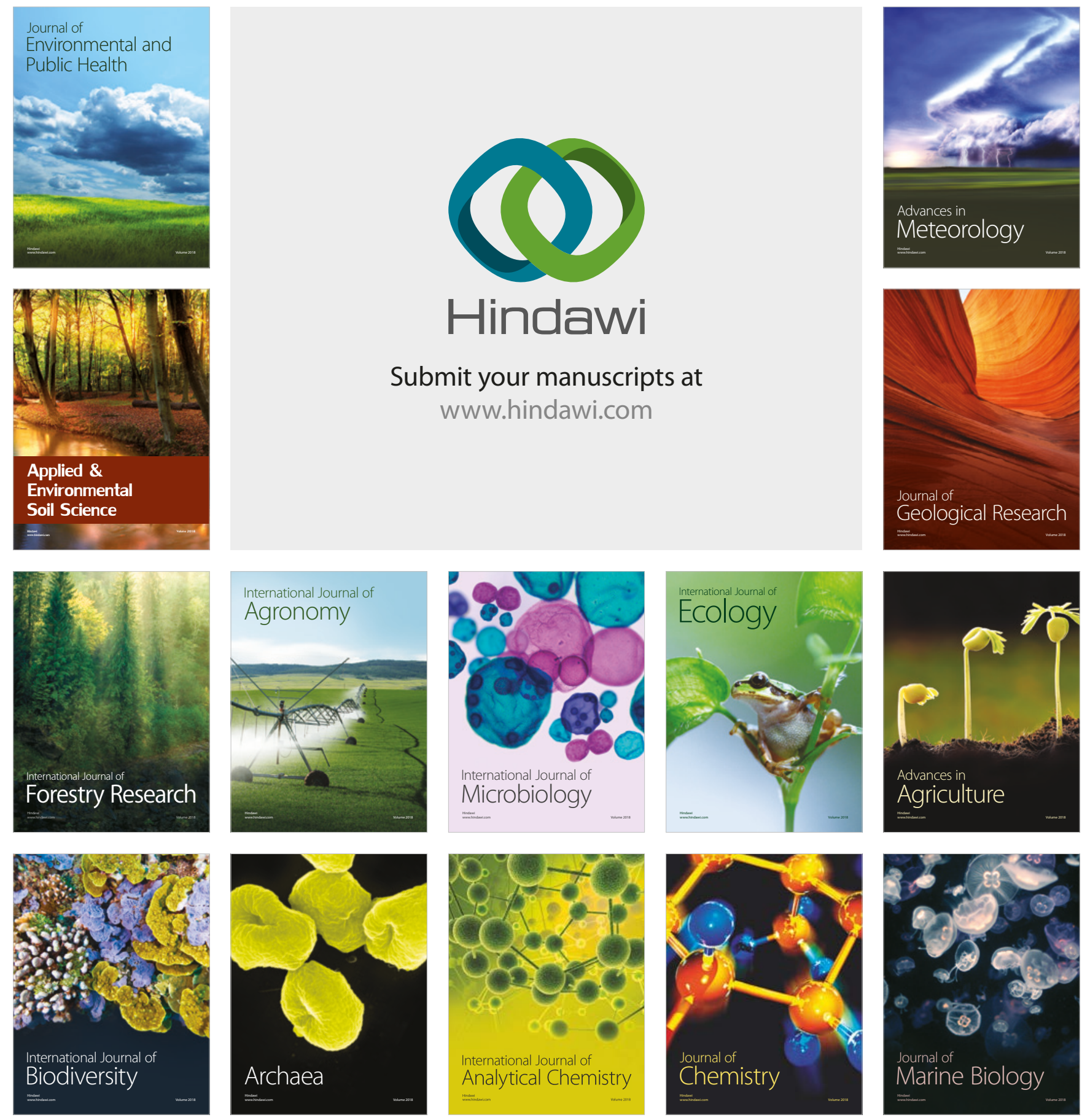